\title{
Vinyl-Deoxyadenosine in a Sarcin/Ricin RNA Loop and its Binding to Ricin Toxin A-Chain
}

\author{
Setu Roday, Suwipa Saen-oon, and Vern L. Schramm ${ }^{\star}$ \\ Department of Biochemistry, Albert Einstein College of Medicine, 1300 Morris Park Avenue, Bronx, \\ NY 10461
}

\section{Abstract}

8-Vinyl-2'-deoxyadenosine ( $8 \mathrm{vdA})$ is a fluorophore with a quantum yield comparable to 2aminopurine nucleoside. $8 \mathrm{vdA}$ was incorporated into a 10-mer stem-tetraloop RNA (8vdA-10) structure to characterize the properties of the base, 8-vinyladenine (8-vA), with respect to adenine as a substrate or inhibitor for ribosome inactivating proteins. Ricin Toxin A-chain (RTA) and Pokeweed Antiviral Protein (PAP) catalyze the release of adenine from a specific adenosine on a stem-tetraloop (GAGA) sequence at the elongation factor (eEF2) binding site of the $28 \mathrm{~S}$ subunit of eukaryotic ribosomes, thereby arresting translation. RTA does not catalyze 8-vinyladenine release from 8vdA-10. Molecular dynamics simulations implicate a role for Arg 180 in oxacarbenium ion destabilization and lack of catalysis. However, $8 \mathrm{vdA}-10$ is an active site analog and inhibits RTA with a $K_{\mathrm{i}}$ value of $2.4 \mu \mathrm{M}$. Adenine is also released from the second adenosine in the modified tetraloop demonstrating an alternative mode for the binding of this motif in the RTA active site. The $8 \mathrm{vdA}$ analog defines the specificities of RTA for the two adenylate depurination sites in an RNA substrate with a GA्AG Atraloop. The rate of non-enzymatic acid-catalyzed solvolysis of 8vinyladenine from the stem-loop RNA is described. Unlike RTA, PAP catalyzes the slow release of 8 -vinyladenine from $8 \mathrm{vdA}-10$. The isolation of 8 -vA and its physicochemical characterization is described.

\section{Introduction}

Ricin is a protein found in castor beans and it inhibits protein synthesis in eukaryotes by depurination of ribosomes at a site where elongation factors bind during translation (1-4). The B-chain of this heterodimeric protein is a lectin that directs the catalytic A-chain to the cell surface. Disulfide bond cleavage releases the A-chain which is then internalized via endocytosis (5). Once inside the cell, retrograde transport shuttles the protein to the endoplasmic reticulum (6). The A-chain is then translocated into the cytosol wherein it binds to a GAGA nucleotide sequence on the sarcin-ricin tetraloop (SRL) of the 28S ribosomal RNA and specifically depurinates the first adenosine $\left(\mathrm{A}_{4324}\right.$ on the rat ribosome; $\mathbf{G A}_{\mathbf{4 3 2 4}} \mathbf{G A}$ in the $5^{\prime} \rightarrow 3^{\prime}$ direction) (Figure 1). The $k_{\text {cat }}$ for RTA activity on rat liver ribosomes is $\sim 1800 \mathrm{~min}^{-1}$ and a single molecule can kill a eukaryotic cell (7). A dose of $\sim 1-2 \mu \mathrm{g} / \mathrm{kg}$ is lethal for dogs. The potency of RTA has been exploited in the assassination of Georgi Markov (8) and an attempt on Alexander Solzhenitsyn's life (9) being the most infamous cases. With a typical content of $10^{5}-10^{7}$ ribosomes, depurination in a rat hepatocyte would be complete in $\sim 40 \mathrm{hrs}$ which is consistent with the rate of fatal ricin poisoning. RTA more recently has also been used as a bioterrorism agent. Inhalation of aerosolized ricin causes rapid and irreversible pulmonary dysfunction. Reliable means of detection (10) and the development of antidotes (11) are important areas of research for this toxin. 
The activity of RTA on small 10-14mer stem-tetraloop RNA substrates at acidic pH has been demonstrated (12) and the $K_{\text {cat }}$ for the hydrolysis of 2'-deoxyadenosine in a hybrid GdAGA tetraloop was determined to be $\sim 16$ fold faster than that for an adenosine tetraloop (13). Kinetic isotope effects (KIEs) on the hydrolysis of an appropriately radiolabeled 10-mer RNA substrate indicate that the reaction proceeds through a dissociative transition state (TS) (14). TS formation at the RTA active site involves leaving group activation, oxacarbenium ion formation and generation of the insipient water nucleophile. Leaving group activation is the major driving force for catalysis. We hypothesized that the incorporation of 8-vinyl-2'deoxyadenosine into an RNA 10-mer structure could provide a useful fluorescent substrate or an inhibitor of RTA. It is likely that the vinyl moiety, with its ability to delocalize electrons, makes 8-vA a better leaving group than adenine. If 8-vA was released, the reaction would become amenable to direct spectroscopic characterization and thus yield a continuous assay system. If not a substrate, an RNA construct with 8-vA could inhibit RTA, and provide useful information in the design of inhibitors. The following sections describe the incorporation of the vinyl nucleoside into RNA, the binding of the modified stem-loop to RTA and a molecular dynamics interpretation of the interaction.

\section{Experimental Section}

\section{Materials and General Experimental}

RTA was purchased from Sigma. Pokeweed Antiviral Protein was purchased from Worthington Biochemicals. Calf intestinal alkaline phosphatase was from Promega (Madison, WI), and phosphodiesterase I was from Sigma Chemical Co. (St. Louis, MO). RNase inhibitors and RNase-free DNase were from Ambion (Austin, TX). Nucleoside phosphoramidites and other reagents for oligoribonucleotide synthesis were purchased from Glen Research (Sterling, VA), except for phosphoramidites attached directly to CPG solid supports, which were obtained from ChemGene Corp. (Ashland, MA). All other chemicals were purchased from Aldrich Chemical Co. (Milwaukee, WI) and were of the highest purity available. These reagents were used without further purification. Purification of reaction intermediates of the phosphoramidite synthetic pathway was completed by flash column chromatography using Merck silica gel 60 (230-400 mesh). Purification by HPLC was performed on a Waters 626 pump with either a 996 photodiode array detector or a 487 dual wavelength detector and using the Millennium software package. RNA concentrations were determined by UV-Vis measurements using a Cary 100 or 300 diode array spectrophotometer from Varian.

\section{Synthesis of the 8-vinyl-2'-deoxyadenosine phosphoramidite}

The synthesis of the vinyl phosphoramidite was carried out as reported by Mély et al. (15). This phosphoramidite can be purchased from Berry and Associates, Inc. However, at the beginning of our work and through the completion of the synthesis, this product was not commercially available.

\section{Synthesis and Purification of 8vdA-10}

The oligonucleotide was chemically synthesized using a phosphoramidite methodology on an Expedite 8900 Nucleic Acid Synthesis System from Perseptive Biosystems. Syntheses were carried out on a $1 \mu \mathrm{mol}$ scale with coupling times extended to $15 \mathrm{~min}$, in the trityl-off mode. The coupling times for guanosine and 8-vinyl-2'-deoxyadenosine were extended to $40 \mathrm{~min}$. Deprotection of the products was accomplished using a concentrated $\mathrm{NH}_{4} \mathrm{OH} /$ ethanol mixture $(3: 1, \mathrm{v} / \mathrm{v})$ and triethylamine trihydrofluoride as described by Chen et al. (12) All products were purified by HPLC using a Waters XTerra Prep MS C18 column $(7.8 \mathrm{~mm} \times 50 \mathrm{~mm})$. These columns are specially designed for purification of oligonucleotides in the trityl-off mode. An ion pairing mobile phase of $50 \mathrm{mM}$ triethylammonium carbonate $(\mathrm{pH} \mathrm{6.4)}$ ) with a gradient from 3 to $80 \%$ of $50 \%$ methanol was employed for elution. The homogeneity of the product was 
confirmed by ion exchange chromatography on a Protein-Pak Q-15 HR DEAE column eluting with $50 \mathrm{mM}$ ammonium acetate (pH 5.0) containing $15 \%$ methanol and $1.0 \mathrm{M} \mathrm{LiCl}$. The nucleotide composition was confirmed by enzymatic digestion of a $50 \mu \mathrm{L}$ aliquot of a $2.5 \mu \mathrm{M}$ solution of the oligonucleotide with 1 unit each of calf intestinal alkaline phosphatase and snake venom phosphodiesterase I overnight at $37^{\circ} \mathrm{C}$, and quantitation of the released nucleosides relative to known standards by HPLC on a Waters Delta-Pak C18 analytical column $(3.9 \mathrm{~mm}$ $\times 300 \mathrm{~mm}$ ) eluted with $50 \mathrm{mM}$ ammonium acetate (pH 5.0) containing 5\% methanol.

Nucleoside and deoxynucleoside standards were used to determine the relative amounts of each component in the digest. Product formation was further confirmed by MALDI-TOF mass spectrometry analysis on an Applied Biosystems 4115 Voyager system. Masses were acquired in the 500-5000 Da range.

\section{Synthesis and Purification of 8-Vinyladenine}

8 -Vinyladenine was isolated from an intermediate of the phosphoramidite synthesis pathway. Thus, a solution of $25 \mathrm{mgs}$ of 5'-dimethoxytrityl-6-N,N-dimethylformamidino-8-vinyl-2'deoxyadenosine in $10 \mathrm{ml}$ of $15 \%$ dichloroacetic acid in dichloromethane was allowed to stir at room temperature for $3 \mathrm{hrs}$. The solvent was then removed in-vacuo and the residue was dissolved in $5 \mathrm{ml}$ of a 1:1 solution of triethylamine in methanol and stirred at room temperature for $24 \mathrm{hrs}$. The solvent was then removed in-vacuo and the crude material was purified by HPLC on a Waters C18 Deltapak analytical column $(3 \mathrm{~mm} \times 300 \mathrm{~mm})$ eluting with $50 \mathrm{mM}$ ammonium acetate ( $\mathrm{pH} 5.0$ ) and a gradient of 3 to $80 \%$ of $50 \%$ methanol over 40 minutes. The collected fractions were pooled, concentrated and finally desalted using a C18 zip-tip prior to ESI mass analysis in the negative mode. ${ }^{1} \mathrm{H} \mathrm{NMR}\left(\mathrm{CD}_{3} \mathrm{OD}, 300 \mathrm{MHz}\right): \delta 5.9(\mathrm{~d}, J=11.3 \mathrm{~Hz}$, $1 \mathrm{H}$, cis-vinyl), 6.45 (d, $J=17.7 \mathrm{~Hz}, 1 \mathrm{H}$, trans-vinyl), $6.95(\mathrm{dd}, J=11.3 \mathrm{~Hz}, J=17.7 \mathrm{~Hz}, 1 \mathrm{H}$, vinyl), 8.35 (s, 1H, C2-H). Calculated Mass: 161.07; Observed Mass: 160.0.

\section{Synthesis and Purification of 8-Vinyladenosine}

The synthesis of 8-vinyladenosine was carried out as reported by Manfredini et al. (16).

\section{Kinetic experiments}

Reaction rates with RTA were determined in $10 \mathrm{mM}$ potassium citrate buffer (pH 4.0) containing $1 \mathrm{mM}$ EDTA. The total reaction volume was $100 \mu \mathrm{L}$. Reactions were started by the addition of RTA at concentrations of $0.5-1 \mu \mathrm{M}$. After incubation of the reaction vials at $37^{\circ} \mathrm{C}$ for the allotted time, the reactions were quenched by inactivating the enzyme with $500 \mathrm{mM}$ potassium phosphate buffer ( $\mathrm{pH} 8.3,100 \mu \mathrm{L}$ of a $1 \mathrm{M}$ solution). The samples were then injected onto a reversed-phase $\mathrm{C} 18$ Waters Delta-Pak guard and analytical column $(3.9 \mathrm{~mm} \times 300 \mathrm{~mm})$ with isocratic elution in $50 \mathrm{mM}$ ammonium acetate $(\mathrm{pH} 5.0)$ containing $5 \%$ methanol, at a flow rate of $1 \mathrm{~mL} / \mathrm{min}$. The enzyme protein is retained on the guard column under these conditions. The extent of hydrolysis of RNA by RTA or by PAP was measured by quantitating the released adenine by monitoring the peak at $260 \mathrm{~nm}$ and using a comparison with standards treated with the same protocol. All substrates used and $8 \mathrm{vdA}-10$ were heated to $80^{\circ} \mathrm{C}$ for $1 \mathrm{~min}$, cooled on ice, and incubated at $37^{\circ} \mathrm{C}$ for 15 min prior to their addition to the assay mix to reduce any variability in the turnover rate that might result from conformational heterogeneity (hairpins vs other forms) in solution. In initial rate experiments, the extent of substrate hydrolysis was less than $15 \%$. Product formation was shown to conform to initial rate conditions for the duration of the assay. Substrate reaction rates were fitted to the Michealis-Menten equation. For $8 \mathrm{vdA}-10$, the binding constant, $K_{\mathrm{d}}$ was assumed to be equal to the competitive dissociation constant $\left(K_{\mathrm{i}}\right)$. The latter was determined by fitting the initial rates to the equation for competitive inhibition, $v=k_{\text {cat }}[\mathrm{S}] /\left[[\mathrm{S}]+K_{\mathrm{m}}\left(1+I / K_{\mathrm{i}}\right)\right]$, where $v$ is the initial reaction rate, $[\mathrm{S}]$ is the substrate concentration, $K_{\mathrm{m}}$ is the Michaelis constant for the substrate $(2.9 \mu \mathrm{M}$ for the competitive substrate, A-10, under the assay conditions), $I$ is the concentration of $8 \mathrm{vdA}-10$, 
and $k_{\text {cat }}$ is the rate of catalytic turnover at substrate saturation. The concentration of $7 \mu \mathrm{M}$ used for A-10 in this assay is $\sim 2.5$ times above its $K_{\mathrm{m}}$, and is a convenient value for competitive inhibitor analysis (17). All reactions with PAP were carried out either in $25 \mathrm{mM}$ HEPES or 25 $\mathrm{mM}$ Tris/ $\mathrm{HCl}$ buffer of $\mathrm{pH} 7.8$ at $25{ }^{\circ} \mathrm{C}$.

\section{Steady State Fluorescence Measurements}

Steady-state fluorescence emission spectra of the 8vA-containing oligonucleotide samples were measured on a SPEX Fluoromax spectrofluorometer using a $3 \mathrm{~mm}$ square cuvette. The emission spectra were recorded over the wavelength range $315-450 \mathrm{~nm}$ with an excitation wavelength of 305 or $310 \mathrm{~nm}$. The spectral bandpass was $5 \mathrm{~nm}$ for all emission spectra. The excitation spectra were recorded over the wavelength range $240-315 \mathrm{~nm}$ by monitoring the emission $380 \mathrm{~nm}$. Inner filter effects were corrected for the sample concentrations that showed a maximal absorbance at the excitation wavelength of $>0.1$. The concentrations of oligonucleotides used were typically in the range of $2.5-5 \mu \mathrm{M}$. The concentrations of 2aminopurine, 8-vinyladenine and tryptophan used for measurement of quantum yield were $<1$ $\mu \mathrm{M}$ and did not require any correction. Quantum yield values (18) were calculated using the equation: $\phi_{\mathrm{VA}}=\phi_{\mathrm{ref}}\left(\mathrm{I}_{\mathrm{VA}} / \mathrm{I}_{\mathrm{ref}}\right) /\left(10^{(\mathrm{ODvA}-\mathrm{ODref}) / 2}\right)$; where $\phi_{\mathrm{VA}}$ and $\phi_{\mathrm{ref}}$ are the quantum yields of 8 -vinyladenine and the reference sample respectively, I refers to the integrated emission intensities and OD to the optical densities at the excitation wavelength of $305 \mathrm{~nm}$.

\section{Determination of the pKa of N9 in 8-Vinyladenine}

1D ${ }^{1} \mathrm{H}$ NMR experiments were performed at $25^{\circ} \mathrm{C}$ on a Bruker DRX $300 \mathrm{MHz}$ NMR spectrometer equipped with pulsed field gradients. 3-(Trimethylsilyl)propionic-2,2,3,3- $d_{4}$ acid sodium salt was used as the internal standard to which the ${ }^{1} \mathrm{H}$ chemical shifts were referenced. A $1 \mathrm{mM}$ solution of 8-vinyladenine in $0.5 \mathrm{ml}$ of $\mathrm{D}_{2} \mathrm{O}$ containing $10 \% \mathrm{CD}_{3} \mathrm{OD}$ as a solubility aid, was used in the study. Titrations were performed by adding small aliquots of $0.1 \mathrm{M} \mathrm{NaOD}$ or $\mathrm{DCl}$. The $\mathrm{p} K_{a}$ value for the $\mathrm{N} 9$ of the 8-vinyladenine was determined by following the $\mathrm{pH}$ dependent chemical shift of the $\mathrm{C} \underline{\mathbf{H}}=\mathrm{CH}_{2}$ proton in the vinyl moiety. The apparent electrode readings were not corrected for deuterium isotope effects. The titration data was biphasic, with the chemical shift of the proton in the vinylic system conclusively reporting on the $\mathrm{N} 9 \mathrm{p} K_{\mathrm{a}}$, whereas the $\mathrm{C} 2$ proton reports a $\mathrm{p} K_{\mathrm{a}}$ that may correspond to protonation of either $\mathrm{N} 1$ or $\mathrm{N} 3$. The data was fitted by nonlinear regression analysis to the following equation: $\delta_{\mathrm{ppm}}=\delta_{1}+$ $\left(\left(\Delta \delta_{2} * 10^{(\mathrm{pka} 1-\mathrm{pH})}\right) /\left(1+10^{(\mathrm{pKa} 1-\mathrm{pH})}\right)\right)+\left(\left(\Delta \delta_{3} * 10^{(\mathrm{pka} 2-\mathrm{pH})}\right) /\left(1+10^{(\mathrm{p} k \mathrm{a} 2-\mathrm{pH})}\right)\right)$; where $\delta_{\mathrm{ppm}}$ and $\delta_{1}$ are the observed chemical shift at a particular $\mathrm{pH}$ and the chemical shift of the unprotonated form, respectively. $\Delta \delta_{2}$ and $\Delta \delta_{3}$ represent differences in shifts from the chemical shifts at the low and high limiting $\mathrm{pH}$ values respectively.

\section{Stochastic deformable boundary (SDB) dynamics}

The starting structure for the simulations described here was based on the crystal structure of RTA in complex with the dinucleotide, adenyl-3',5'-guanosine (ApG: PDB Id:1APG). (19) Due to the lack of a crystallographic water molecule in the X-ray structure, an important catalytic water molecule was placed into the active site explicitly. Robertus et al. have reported the crystal structure of apo-ricin A and B-chain at $2.5 \AA$ resolution (PDB Id: 2AAI) (20) and identified one water molecule (WAT 323) within the active site pocket as the catalytic water forming strong interactions with Glu177 and Arg180. Therefore, we modeled WAT323 into the active site of the RTA/ApG complex. We also modelled 8-vinyladenyl-3',5'-guanosine (vApG) in complex with RTA/vApG using the RTA/ApG complex structure by substituting the $\mathrm{C} 8$ position of adenine ring with vinyl group. 2'-deoxyadenyl-3',5'-guanosine (dApG) and the vinyl counterpart, 2'-deoxy-8-vinyladenyl-3',5'-guanosine (vdApG) were also modelled in similar fashion. 
To investigate the local structural and interaction characteristics of dinucleotide binding to the active site of RTA, the stochastic boundary approach (21) was applied and all four simulations (RTA/ApG; RTA/vApG; RTA/dApG and RTA/vdApG) were carried out with the CHARMM program. (22) Hydrogen atoms were built using the 'hbuild' module in CHARMM. The simulations were run with the truncated protein SDB simulations. The simulation system contained a spherical selection of residues centered around the $\mathrm{C} 1$ ' atom of adenine dinucleotide. All protein residues with at least one atom within 18 Å of the center were selected. Protein residues outside the spherical zone were held fixed throughout the entire SDB simulation. The systems were then solvated by the superimposing a $23-\AA$-radius sphere of water (Jorgensen's TIP3P model) (23) and deleting any added water molecule whose oxygen atom was within $2.8 \AA$ distance of another non-hydrogen atom. One chloride ion was added to neutralize the system. The structure of the model set up for SDB simulation is shown in Figure $\mathrm{S} 1$ in supporting information. Water molecules were minimized by applying a harmonic restraint of $10 \mathrm{kcal} \mathrm{mol}^{-1} \AA^{2}$ with 500 steps of steepest descent (SD) minimization. All atoms within the spherical 18 - $\AA$-radius were then minimized with 500 steps each of steepest descent (SD) and adopted basis Newton Raphson (ABNR) minimization.

All atoms of the system were treated molecular mechanically, using the CHARMM22 allatoms force field. Throughout, a 5- $\AA$ buffer zone was defined as all atoms further than $18 \AA$ away from the center of the sphere, in which the non-solvent heavy atoms were harmonically restrained to their crystal coordinates with the force constants. During the dynamics simulations, Langevin dynamics were applied to the buffer region, using friction coefficients of $250 \mathrm{ps}^{-1}$ for non-hydrogen protein atoms and $62 \mathrm{ps}^{-1}$ on water oxygen atoms. (24) A deformable boundary potential was applied on the water oxygens. Simulations were run with a time step of $1 \mathrm{fs}$ and the SHAKE algorithm (25) with a tolerance of $10^{-8}$ was used to constrain all bonds involving hydrogen atoms. Nonbonded interaction energies and forces were smoothly shifted to zero at a cutoff of $12.0 \AA$ by the atom-based truncation method with a force-shifting function. The nonbonded pair list was generated for atoms within a $12 \AA$ cutoff and the nonbonded list was updated heuristically. The force shift option causing the interaction energies and the force to vanish smoothly at the distance of $10 \AA$ was used. The relative dielectric constant was set to 1.0. Simulation systems were heated from 100 to $300 \mathrm{~K}$ over 20 ps. The temperature was progressively increased and the systems were then equilibrated for $80 \mathrm{ps}$ at $300 \mathrm{~K}$ and continued for the production run for a further $300 \mathrm{ps}$. Trajectories were saved every $10 \mathrm{fs}$.

\section{Results and Discussion}

\section{Incorporation of 8-vinyl-2'-deoxyadenosine (8vdA) into RNA}

Mély et al. have reported the synthesis of 8-vinyl-2'-deoxyadenosine (8vdA) and its phosphoramidite and subsequent incorporation into DNA (15). We followed their synthetic route but aimed to incorporate the novel nucleoside phosphoramidite into a small 10-mer stemtetraloop RNA, 5'-CGCG(8vdA)GAGCG-3' (8vdA-10). It should be noted, however, that the modified nucleoside is flanked by two guanosines in this sequence and that Mẻly et al. were only able to incorporate this residue into DNA when the flanking residues were either A, T or C. When the flanking residue was $\mathrm{G}$, a compound of mass $\Delta \mathrm{M}=+151$ was obtained which was consistent with the formation of a guanine adduct. This presumably results from a 1,4 type Michael addition of the N7 of the 2'-deoxyguanosine phosphoramidate on the $\alpha, \beta$-unsaturated vinyladenine system. In our approach, every residue other than the vinyl nucleoside was a ribonucleoside, thus the greater inherent acid stability of the guanosine phosphoramidate during RNA synthesis was proposed to decrease the extent of Michael addition. Another concern was the nucleophilic addition of ammonia to the vinyl moiety during deprotection of the DNA from the solid support. This was reduced by allowing the deprotection reaction for 
$4 \mathrm{hrs}$ at room temperature instead of the standard 16-18 hrs. This problem was also encountered in our initial synthesis but was circumvented by using a 3'-end nucleoside that was derivatized on an oxalyl-controlled pore glass (CPG) solid support (26) instead of the standard succinylCPG. The former has the advantage of being labile to ammonia-free cleavage with basic reagents like triethylamine which are not nucleophilic. Further, we used rapid base labile protecting groups on the $\mathrm{C}, \mathrm{G}$ and A residues. 8-vinyl-2'-deoxyadenosine is both acid labile (hydrolysis of the glycosidic bond) and base susceptible (addition to the vinyl moiety) and thus care is needed in its exposure time to potentially degradative reagents. A solution of $0.5 \mathrm{M}$ iodine in pyridine is the standard reagent used in DNA synthesis to oxidize the phosphite to the phosphate. In our synthesis of RNA, we replaced this with a solution of $2 \mathrm{M}$ tert-butyl hydroperoxide (TBHP) in toluene/dichloromethane (27) to avoid exposure of the vinyl moiety to pyridine. We also used 3\% dichloroacetic acid in dichloromethane, a mild acid, to effect the removal of the 5'-dimethoxytrityl groups. The synthesis of 8vdA-10 was carried out on a 3 $\mu$ mole scale with a yield of $\sim 20 \%$. MALDI mass spectrometry and enzymatic digestion with snake venom phosphodiesterase and alkaline phosphatase confirmed the incorporation of the vinyl nucleoside into the RNA and the composition of the 10-mer species. This is the first report of the incorporation of a vinyl nucleoside into an RNA scaffold.

\section{Fluorescence of 8-vinyl-2'-deoxyadenosine within the stem-loop RNA, 8vdA-10}

The emission spectrum of $8 \mathrm{vdA}$ in the oligonucleotide, $8 \mathrm{vdA}-10$ has a maximum at $388 \mathrm{~nm}$. The quantum yield of the oligonucleotide was determined relative to 2-aminopurine (28) and compared with similarly determined quantum yields of 8-vinyl-2'-deoxyadenosine, 8vinyladenosine and 8-vinyladenine. The quantum yield of $8 \mathbf{v d A - 1 0}$ was found to be quenched 270 fold relative to that of the vinyl deoxyribonucleoside (Figure 2A,2B and Table 1). The spectroscopic behavior of $8 \mathrm{vdA}$ in the hairpin RNA is governed by intra-tetraloop conformational factors. It is known that the 'GAGA' tetraloop adopts a structure in solution such that the three purine rings on the 3'-side (ie. A, G and A) are stacked upon each other (Figure 2D) (29,30). A similar conformation is likely for the 'G8vdAGA' tetraloop as well and along with the two flanking guanosines explains the dramatic quenching of the vinyl nucleoside fluorescence in the RNA. Further, the emission maximum of the free base, 8-vinyladenine, was found to be at $378 \mathrm{~nm}$ (the synthesis of 8-vA is described in a later section) and that of the vinyl nucleosides (both ribo and deoxy) at $384 \mathrm{~nm}$. The $4 \mathrm{~nm}$ red shift of fluorescence of the 8-vinyladenine moiety in RNA suggests that it is solvent exposed. An examination of the tetraloop structure reveals that the turn in the phosphate backbone between the first guanosine of the loop and the second adenosine (or $8 \mathrm{vdA}$ ) disposes these residues in spatially different orientations thus providing solvent accessibility to the first purine of the triple base stack. A temperature dependence of the fluorescence intensity of $8 \mathrm{vdA}-10$ was also carried out (Figure $2 \mathrm{C}$ ). A two fold increase in intensity was observed when the temperature was raised from 22 ${ }^{\circ} \mathrm{C}$ to $50{ }^{\circ} \mathrm{C}$. The emission maximum was also found to be blue shifted by $6 \mathrm{~nm}$. The tetraloop is clearly more dynamic at higher temperatures resulting in an unstacking of the 8-vinyadenine moiety. The disruption of the quenching/stacking effect of the adjacent guanosines at higher temperatures results in the observed changes in fluorescence intensities. At temperatures greater than $60{ }^{\circ} \mathrm{C}$, the $8 \mathrm{vdA}-10$ starts undergoing intrinsic chemical hydrolysis and releases 8 -vinyladenine resulting in a dramatic increase of fluorescence intensity.

Quenching mechanism for 8-vA stacked with A, T and C has been studied theoretically in dimer and trimer species and compared with the observed quenching of its quantum yield when incorporated into oligonucleotides bearing $\mathrm{A}, \mathrm{T}$ or $\mathrm{C}$ adjacent to it in the sequence (31). However, the quenching mechanism for 8-vA flanked with $\mathrm{G}$ was not studied since an oligonucleotide sequence with a $\mathrm{G}$ adjacent to 8 -vA could not be synthesized. Our successful synthesis of $8 \mathrm{vdA}-10$ with the vinyl nucleoside adjacent to two guanosines and the characterization of its spectral properties in the RNA provides a good experimental 
oligonucleotide model for comparison with a theoretical analysis of the 8-vA $\mid \mathbf{G}$ quenching mechanism.

\section{Substrate Activity of $8 \mathrm{vdA}-10$ with RTA}

$8 \mathrm{vdA}-10$ was tested as a substrate for RTA at $\mathrm{pH} 4.0$ and $37{ }^{\circ} \mathrm{C}$ with assay conditions that have been reported previously for stem-loop substrates of RTA $(10,11)$. The reaction was monitored by HPLC using dual wavelength detection at $260 \mathrm{~nm}$ and $305 \mathrm{~nm}$. (The $\lambda_{\max }$ of $8 \mathrm{vdA}$ is 295 $\mathrm{nm})$. The initial conditions followed the reaction for $1 \mathrm{hr}$ at $37^{\circ} \mathrm{C}$. No release of 8 -vinyladenine was observed. However, HPLC showed the release of adenine under the prolonged conditions $(\sim 12 \mathrm{hrs})$. A new peak at $305 \mathrm{~nm}$ was also observed under these conditions and was assumed to be that of 8-vinyladenine (Figure 3). Control incubations at $\mathrm{pH} 4.0$ without RTA indicated no release of adenine. However, both control and RTA samples released similar amounts of 8-vinyladenine on prolonged incubations indicating a slow non-enzymatic solvolysis of 8vinyladenine. Although $8 \mathrm{vdA}-10$ is not a substrate for RTA at the primary depurination site, enzymatic release of adenine from the second site confirms that it binds at the catalytic site. Further, control experiments (10 mM HEPES buffer) at $\mathrm{pH} 7.0$ do not release either adenine or 8-vA on prolonged incubation. MALDI analysis also established masses corresponding to unreacted RNA, deadenylated RNA and the devinylated RNA (Figure 3).

RTA catalyzes the specific depurination of the first adenosine in synthetic stem-loop RNA and DNA molecules containing a GAGA tetraloop motif. Chen et al. showed that the $k_{\text {cat }}$ for the depurination of an all DNA stem-tetraloop substrate, dA-10 at this site was $\sim 0.38 \mathrm{~min}^{-1}$ and the $K_{\mathrm{m}}$ for its binding was $\sim 2.6 \mu \mathrm{M}$ (12). Prolonged incubation of dA-10 with RTA caused the release of a second equivalent of adenine as a result of both 2'-deoxyadenosine residues in the DNA tetraloop being hydrolyzed by RTA. The kinetic constants of depurination at the second site were determined using a DNA 10-mer, dR-10, where an abasic residue, 1,2dideoxy-D-ribose, was substituted for the first dA in the d(GAGA) tetraloop (32). The $k_{\text {cat }}$ for depurination at the second site $\left(\mathrm{k}_{1}\right)$ was $\sim 0.46 \mathrm{~min}^{-1}$ and the $K_{\mathrm{m}}$ was $\sim 160 \mu \mathrm{M}$. Chen et al. determined the specificity constant, $k_{\mathrm{cat}} / K_{\mathrm{m}}$, for depurination at the second site to be $\sim 60$-fold lower than at the first. However, this experiment does not provide a rate for depurination at the second site while the first remains intact. In addition, the structure of the tetraloop with an abasic site ('GabGA') is different from an intact GAGA tetraloop. Thus, Chen's specificity constant comparison for the two adenosines is an approximation.

Adenine release from $8 \mathrm{vdA}-10$ could occur before or after the oligonucleotide is depurinated at the vinyl site. If the $8 \mathrm{vdA}-10$ binds to RTA and only deadenylation takes place, an accurate rate of depurination from the second site could be obtained. And if the binding constant of $8 \mathrm{vdA}-10$ is similar to A-10, the second site depurination rate could be directly compared with the rate of adenine release from the first site of A-10, thus providing a true discrimination of specificities for the two sites. Scheme 1 shows the fate of $8 \mathrm{vdA}-10$ upon binding to RTA. Literature suggests that RTA can cause both deadenylation of the first adenosine in a GAGA tetraloop and non-specific deadenylation and deguanylation from other sites in stem-loop RNA (33). This study uses synthetic 28-mer stem-loop RNA and 5S rRNA as substrates and reports deadenylation and deguanylation on the basis of denaturing gels. In our work, we determine the rates of depurination at individual sites.

\section{Binding of 8vdA-10 to RTA: Competitive Inhibition and Fluorescence Studies}

The dissociation constant of 8vdA-10 for RTA, $K_{\mathrm{i}}$, was determined by using a 10-mer stemloop RNA, A-10, as a competitive substrate. Under assay conditions where RTA satisfies initial rate conditions on $\mathbf{A - 1 0}$ and does not release either adenine or 8-vinyladenine (8-vA) from 8vdA-10, the competitive assay gives a $K_{\mathrm{i}}$ (Figure $4 \mathrm{~A}$ ) of $2.4 \pm 0.34 \mu \mathrm{M}$ for $8 \mathrm{vdA}-10$, a value 
close to the $K_{\mathrm{m}}$ for A-10 $(2.9 \mu \mathrm{M})$. Thus, $8 \mathrm{vdA}-10$ binds as well as the A-10 substrate. However, despite its good binding, $\mathbf{8 v d A}$ is not hydrolyzed.

Fluorescence spectroscopy was also employed for a direct determination of the binding constant of $8 \mathrm{vdA}-10$ and to explore the base-flipping mechanism. If $8 \mathrm{vdA}-10$ were to adopt a hairpin tetraloop structure with a triple purine stack and if RTA were to alter the torsion angle of the glycosidic bond of the vinyl nucleoside, it would disrupt this stack, make the vinyladenine more solvent exposed and increase the fluorescence of the "flipped-out" bound species through disruption of the quenching effect of the adjacent guanosines. However, a titration of increasing concentrations of RTA with a fixed concentration of 8vdA-10 only caused an increase of about $15 \%$ in fluorescence intensity at saturation (Figure 4B) making it difficult to determine the $K_{\mathrm{d}}$ of $8 \mathrm{vdA}-10$ directly from the fluorescence experiment. The fluorescence of the bound species was blue shifted by about $5 \mathrm{~nm}$ suggesting an unstacking of the 8-vinyladenine (similar to the blue shift in the temperature dependence experiment discussed earlier). However, the small increase in fluorescence suggests that the flipped out base becomes stacked between the two active site tyrosines (Tyr 80 and Tyr 123) which then efficiently quench its fluorescence. Thus, the overall change in fluorescence intensity upon binding is minimal since the vinyladenine moves from one stacked environment in the tetraloop to another in the hydrophobic RTA active site.

\section{Binding of the vinyladenine moiety in the RTA active site: Molecular Dynamics Simulations}

Attempts in crystallizing either 8-vA or 8vAde with RTA were unsuccessful. Modeling of 8vA in the crystal structure of RTA bound to adenine (Figure 5) indicates potential steric clashes with the $\alpha$ and $\beta$ carbons of Asn 122, the aromatic ring of Tyr 123 and the carbonyl oxygen of Gly 121. It has been suggested that RTA might use a base-flipping mechanism to dock its target adenosine in the active site before depurination (34). In the uncomplexed structure of the Sarcin Ricin Loop (SRL) RNA, the glycosidic bond of the susceptible adenosine, $\mathrm{A}_{4324}$, is anti and the adenine base is involved in a triple purine stack with the bases of the adjacent guanosine and adenosine. However, the crystal structure of ricin bound to a substrate analog, formycin monophosphate (FMP), shows that the glycosidic bond is syn and the base stacks between two tyrosines, Tyr 80 and Tyr 123 (19). It is proposed that RTA recognizes the RNA with the susceptible adenosine in the anti conformation, flips it to the syn and finally catalyzes the hydrolytic reaction. Mély et al. carried out a NOESY study and determined that both syn and anti conformations were present for the base in 8-vinyl-2'-deoxyadenosine (15). It is possible in the context of an RTA bound structure that a $\mathrm{C} 8$ substituent forces the adenine ring to adopt an orientation (syn or anti) where steric factors preclude catalysis. Although competitive inhibition of A-10 hydrolysis by $\mathbf{8 v d A - 1 0}$ and the release of adenine from its second site both establish that this stem-loop RNA is an active site analog, we carried out molecular dynamics simulations to understand the surprising lack of catalysis.

The X-ray structure of RTA bound to the dinucleotide adenyl-3',5'-guanosine, ApG (PDB Id: 1APG) (19) was used as the starting model structure for the MD simulations. Two independent simulations were run, one with ApG and the other with the dinucleotide, vApG where the adenosine is replaced by 8 -vinyladenosine. The conformational binding mode for the adenine and ribose rings of adenosine is known from the $\mathrm{X}$-ray structure. A comparative analysis of the simulated RTA- ApG and RTA-vApG complexes was carried out to determine the origin of the differences in catalysis between adenosine and 8-vinyladenosine. MD simulations with ApG have been reported in the literature and our ApG simulation model was in good accord with those results (35). The simulation structures averaged over 300 ps show dramatic differences between the bound orientations of adenine (in ApG) and 8-vA (in vApG) in the hydrophobic pocket of RTA (Figure 6). The two invariant residues lining this pocket are Tyr 80 in a $\beta$-strand and Tyr 123 in an $\alpha$-helix. Their spatial disposition is coupled with the structural 
changes that accompany base binding. In particular, the backbone and side-chain dihedral angles of Tyr 80 undergo transitions that accompany the change in the dihedral angle of the $\mathrm{C}-\mathrm{N}$ glycosidic bond in adenosine and 8-vinyladenosine. This dihedral angle governs the orientation of base binding in the active site. As shown in Figure 5, the hydrophobic pocket of RTA is tight such that the introduction of the vinyl substituent on the $\mathrm{C} 8$ of adenosine would result in several steric clashes if it was bound in the same orientation as the adenine ring in the X-ray structure, $1 \mathrm{APG}$. The $300 \mathrm{ps}$ MD simulation of $\mathrm{vApG}$ shows that these steric factors indeed play a major role since the glycosidic bond torsion in vinyladenosine rotates by $33^{\circ}$ compared to the adenosine. This allows the vinyl moiety to be accommodated such that steric clashes with residues Gly 121, Asn 122 and Tyr 123 are avoided (See Figure 6). The dihedral angles that orient the aromatic rings in the two tyrosines change significantly to accommodate the vinyladenine in the most favorable and least sterically hindered orientation. The side-chain dihedral angle of Tyr 123 rotates from $150^{\circ}$ in $\mathrm{ApG}$ to $82^{\circ}$ in vApG and that of Tyr 80 changes from $82^{\circ}$ to $-177^{\circ}$ respectively. It is clear from the MD simulation that both the 8 -vinyladenine and the catalytic site undergo conformational changes from both the crystal structure and the simulation structure of the RTA-ApG complex. Apart from the differences in stacking, the electrostatic interaction of Arg 180 with N3 of the base is preserved in both adenosine and 8vinyladenosine. However, for 8-vinyladenine, the contacts of N6 with Gly 121 and Val 81 and of the $\mathrm{N} 1$ with $\mathrm{Val} 81$ are also weakened suggesting that stacking is the dominant force for binding. It must be noted however that the simulation structure of ApG also shows several changes in the active site compared to its crystal structure. Nevertheless, these are not as dramatic as seen for accommodation of the vinyladenine. The observed differences between the simulation structure and the $\mathrm{X}$-ray structure are a result of the optimization of non-bonded interactions (electrostatic and van der Waals). In addition, as pointed out by Olson, ApG is a weak binding ligand such that multiple binding modes are possible (35).

Having established an alternate binding mode for the 8-vinyladenine, an analysis of the interactions around the ribose ring was carried out. This analysis was compared with that of the adenosine ribosyl in the RTA-ApG complex. The ribose pucker configuration is 2'-endo for both adenosine and 8-vinyladenosine. However, the orientation of the ribosyl ring in the latter is dramatically different. In the ApG complex, the OE1 atom of Glu 177 is $3.7 \AA$ away from the 2'-hydroxyl and $4.6 \AA$ from the $\mathrm{C} 1$ ' of the ribose. In the vApG complex, these distances are $7.4 \AA$ and $6.3 \AA$ respectively. Glu 177 is a catalytic residue in the RTA active site that has been implicated in a) an oxacarbenium ion stabilizing role at the transition state and b) a general base role in abstracting a proton from a nucleophilic water molecule in the active site (36). Glu 208 is another catalytic residue that has been implicated in catalysis (36). A weakening of ribosyl interactions with these two residues may lead to a loss of oxacarbenium ion stabilization and thus lack of catalytic efficiency. However, literature reports an E177A mutant that only lost catalytic efficiency by 20 -fold over the wild type RTA. In addition the $2{ }^{3}{ }^{3} \mathrm{H}$ KIE for hydrolysis of adenosine in a model 10-mer stem-loop RNA is reported to be 1.012 (14). It has been shown that polarization of 2'-hydroxyl group leads to a higher value of the $2{ }^{\prime}{ }^{3} \mathrm{H}$ KIE by a lengthening of the $\mathrm{C} 2$ '- $\mathrm{H} 2$ ' bond which in turn allows substantive hyperconjugative overlap between the $\sigma \mathrm{C} 2$ '- $\mathrm{H} 2$ ' bond and the empty p-orbital on the anomeric carbon ( $\mathrm{Cl}^{\prime}$ ) of the oxacarbenium ion (37). Since this value is small in case of the RNA hydrolysis it is likely that Glu 177 in RTA does not operate via this mechanism. Instead it may directly stabilize the oxacarbenium ion by electrostatic interaction. Based on these experimental results, it was thought that disruption of interactions with Glu 177 would lead to a loss of catalytic efficiency but not complete abolishment of activity. However, the latter is observed in the case of the vinyl RNA, 8vdA-10.

A comparative analysis of distances and interaction energies of the RTA-ApG and RTA-vApG complexes then led to another interesting observation (See Tables 2 and 3 and Figure 7). The Arg 180 nitrogens, $\mathrm{NH} 1$ and NH2 are $~ 5-6 \AA$ away from the ribose ring oxygen in case of both 
the X-ray and simulated structures of ApG. However, these distances close in to 3.4 and 3.1 $\AA$ respectively in case of the simulated structure of the vinyladenyl compound, vApG. The analysis of interaction energies shows that the total energy for the ribose-Arg 180 interaction is $\sim 4 \mathrm{kcal} / \mathrm{mol}$ lower for $\mathrm{vApG}$ compared to ApG suggesting a clear electrostatic stabilization of the ribosyl conformation in the vinyl dinucleotide.

Arg 180 is a conserved residue in a family of ribosome inactivating proteins and mutations of this residue are severely detrimental to catalytic activity. A contribution of $4 \mathrm{kcal} / \mathrm{mol}$ can lead to $\sim 1000$ fold loss of catalytic activity [from $\Delta \Delta \mathrm{G}=-\mathrm{RT} \ln \left(k_{1} / k_{2}\right)$ ]. It is reasonable to assume that in case of $\mathrm{vApG}, \mathrm{Arg} 180$ plays a role in ground state stabilization (electrostatic attraction) of the ribose and/or transition state destabilization (repulsion) of the oxacarbenium ion.

Enzymes such as purine nucleoside phosphorylase (PNP) have been shown to exhibit coupled protein and substrate motion such that the purine 5'-hydroxyl and ribose ring oxygen and the nucleophile phosphate oxygen form a repulsive environment that promotes the lone pair of electrons to push from the ring oxygen to $\mathrm{Cl}^{\prime}$ ' resulting in oxacarbenium ion formation (38). In the case of RTA-vApG complex, coupled motion of protein and substrate allows the vinyladenine base to bind in an altered orientation. Coupled protein and ribose motion then brings the Arg 180 in close proximity to the ribose ring oxygen. This would 1) serve to stabilize the ribose in the ground state but 2) be destabilizing for oxacarbenium ion formation and 3) result in loss of catalytic activity.

Thus, the entropic cost of organizing the 8-vinyladenine in the active site is coupled with the change in ribosyl orientation. The simulation model provides a rationale for the observation that $8 \mathrm{vdA}-10$ binds to RTA but is not hydrolyzed. Although the simulation only involves a dinucleotide, similar changes in ribosyl geometry in case of the RTA bound RNA structure can lead to a loss of catalytic activity. As pointed out by Pande et al., the unique feature of the GNRA class of tetraloops is a cooperative relationship between 3 -endo $\rightleftharpoons 2$ '-endo and closedloop $\rightleftharpoons$ open-loop transitions (39). The $2^{\prime}$-endo pucker modes expand the loop backbone and allow extension of the base away from the loop. It is reasonable to assume that in the dynamic open loop conformation with the depurination site base flipped out, changes in ribosyl geometry similar to those observed in the dinucleotide structure, $\mathrm{vApG}$, can also be allowed in the larger RNA structure without a significant distortion of the orientations of the RNA chain on the 5' and 3'-sides of the vinyladenosine. This also seems plausible given the 1 Å expanded backbone of the $8 \mathrm{vApG}\left(5^{\prime} \mathrm{O}\right.$ to 3 '-P distance of $5.6 \AA$ ) compared to the ApG structure.

MD simulations were also carried out for the 2'-deoxyadenyl guanosine (dApG) and its vinyl counterpart, 8-vinyl-2'-deoxyadenyl guanine (vdApG). The binding of the vinyladenine base involves similar motion of Tyr 80 (side chain dihedral changes from $81^{\circ}$ to $177^{\circ}$ ) and Tyr 123 (side chain dihedral changes from $92^{\circ}$ to $85^{\circ}$ ) as was described in the ribose case. The N-C glycosidic bond torsion (O4'-C1'-N9-C4) rotates from $31^{\circ}$ in $\mathrm{dApG}$ to $-27^{\circ}$ in vdApG. The lack of catalysis in the case of the 2'-deoxy-8-vinyladenosine can again be rationalized on the basis of similar observations that Arg 180 forms a strong electrostatic interaction with the deoxyribose ring oxygen in vdApG but not in $\mathrm{dApG}$ (energy difference $\sim 4 \mathrm{kcal} / \mathrm{mol}$ ). The Arg 180-deoxyribose interaction is similar to the one observed with ribose. Thus, both sets of simulations show the same trends. Another interesting observation is that the geometry of the deoxyribosyl ring is 3'-endo for $\mathrm{vdApG}$ whereas it is 2'-endo for $\mathrm{dApG}$. The interaction distances and energies are shown in Tables 2 and 3 respectively. Details of the simulation have been included in the (supporting information Figure S2 and Table S1).

Our MD simulations point toward an interesting mechanism by which RTA maintains its specificity for hydrolyzing adenosine. The hydrophobic pocket can bind a variety of base analogs (11) and is also involved in leaving group activation but not all molecules that bind 
are turned over. Thus, it is likely that in the RTA-8vdA-10 structure, Arg 180 is destabilizing for oxacarbenium ion formation resulting in a non-productive complex. This scenario is reminiscent of transition state destabilization in the DNA repair enzymes by 2'-fluoro substituted nucleosides which form non-productive complexes (40). Our theory of the lack of catalysis of $8 \mathrm{vdA}-10$ by RTA thus invokes both steric and electronic factors. The alteration in 8 -vinyladenine binding is coupled with the reorientation of ribose/deoxyribose rings (in vApG/ vdApG respectively) such that the Arg 180 interaction with sugar ring oxygen is only observed in the vinyl nucleoside simulations. Figure 8 shows a schematic model for these observations.

\section{Characterization of adenine release from the second site of the tetraloop of 8vdA-10}

RTA-catalyzed adenine release for $8 \mathrm{vdA}-10$ was found to be slow with a $k_{\text {cat }}$ of $0.023 \pm 0.004$ $\min ^{-1}, K_{\mathrm{m}}$ of $205 \pm 64 \mu \mathrm{M}$ and a $k_{\text {cat }} / K_{\mathrm{m}}$ of $2.03 \pm 0.03 \mathrm{M}^{-1} \mathrm{~s}^{-1}$ (See Figure S3A in supporting information). Chen et al. determined the $k_{\text {cat }} / K_{\mathrm{m}}$ for the hydrolysis of stem-loop RNA 10-mer, A-10 to be $1.7 \times 10^{4} \mathrm{M}^{-1} \mathrm{~s}^{-1}$ and the $k_{\text {cat }}$ and $K_{\mathrm{m}}$ to be $\sim 4 \mathrm{~min}^{-1}$ and $4.1 \mu \mathrm{M}$ respectively (12). A comparison of the $k_{\text {cat }} / K_{\mathrm{m}}$ of A-10 with $8 \mathrm{vdA}-10$ indicates that the recognition of the second adenosine in the tetraloop by RTA is $\sim 8000$-fold lower than the first site.

Since the specificity of RTA for the first adenosine is much higher than the second, other depurination events follow the first one. The conformation of the tetraloop changes once the first adenosine is cleaved, resulting in altered susceptibility for the second adenosine. As described above, Chen et al. observed a $k_{\text {cat }}$ of $\sim 0.46 \mathrm{~min}^{-1}$ for second site adenine release from $\mathrm{dR}-10$, a substrate that was abasic in the primary site. This rate is $\sim 20$ fold faster than that observed for adenine release from $8 \mathrm{vdA}-10$ (which is intact at the primary site).

Adenine release from the second adenosine on the tetraloop of $8 \mathrm{vdA}-10$ suggests binding to RTA in two modes. One positions the 8-vA (8-vinyladenine) in the depurination site using the normal stem-loop geometry and another reverse-disposes the 8 -vA and the adenine by a $180^{\circ}$ rotation of the tetraloop with respect to the catalytic site. Stem-tetraloop structures such as $8 \mathrm{vdA}-10$ are known to be thermodynamically extremely stable. However it is possible that stem-slippage could also alter loop structure. We calculated the secondary structures of the related 10-mer stem-loop molecule A-10 with the programs mFold (version 2.3; structure calculated in $1 \mathrm{M} \mathrm{NaCl}$ at $25^{\circ} \mathrm{C}$ ) (41) and RNAshapes (42). An alternate geometry was found that results from slippage of two residues in the stem such that the second adenosine can be positioned in the RTA catalytic site for depurination. This alternate structure, TL2, (with a tetraloop, two base-pairs and a two residue overhang) is $6.1 \mathrm{kcal} / \mathrm{mol}$ higher in energy than the most stable structure with the tetraloop and 3 base-pairs, TL1 (Figure 9). However, the difference in catalytic rates of depurination at the two sites (calculated using the expression: $\Delta \Delta \mathrm{G}^{\mathrm{TS}}=-\mathrm{RT} \ln \left(k_{1} \mathrm{~h} / \mathrm{k}_{\mathrm{B}} \mathrm{T}\right) /-\mathrm{RT} \ln \left(k_{2} \mathrm{~h} / \mathrm{k}_{\mathrm{B}} \mathrm{T}\right)$ where $k_{1}$ and $k_{2}$ are the catalytic rate constants at the two sites) is $\sim 3.1 \mathrm{kcal} / \mathrm{mol}$ which is less than the barrier to interconversion between TL1 and TL2. Thus, the direct recognition of a slipped structure by RTA or an enzyme promoted slippage is unlikely. Disruption of base-pairs and rearrangement of secondary structure on the enzyme is likely to be more energetically demanding than in solution. A simple $180^{\circ}$ rotation of the tetraloop more easily explains both the high $K_{\mathrm{m}}$ and low turnover at the second site.

Crystal structures of RTA bound either to small molecules such as adenine and formycin monophosphate (19) or simulation models of hexamer, CGAGAG (35), indicate a single site for adenine depurination. Binding of $\mathbf{8 v d A - 1 0}$ gives a $K_{\mathrm{i}}$ of $2.4 \mu \mathrm{M}$ which is a dissociation constant with respect to $\mathbf{A}-\mathbf{1 0}\left(K_{\mathrm{m}}=2.9 \mu \mathrm{M}\right)$. This thermodynamic constant represents similar binding of 8vdA-10 and A-10. However, in catalysis at the second site, the $K_{\mathrm{m}}$ of the vinyl RNA is $205 \mu \mathrm{M}$. Slow substrates of RTA are known to be in thermodynamic equilibrium: thus, $K_{\mathrm{m}}$ is also a dissociation constant. Therefore, adenine depurination of $\mathbf{8 v d A - 1 0}$ likely involves binding of the stem-loop in a 3' $\rightarrow$ ' ' orientation opposite to that of A-10. Kinetic data with 8vdA-10 indicates that the catalytic specificity $\left(k_{\text {cat }} / K_{\mathrm{m}}\right)$ for the first adenosine in a 10-mer 
stem-tetraloop substrate is almost three orders of magnitude more favorable than the second site.

It is not clear if second site deadenylation is physiologically relevant. However, our observations are relevant to inhibitor design in that it may be desirable to include nonhydrolysable adenine isosteres at two sites in the tetraloop. Depurination reactions can occur in the same active site as a result of recognition of multiple conformations of the tetraloop. Catalytic rate efficiency at the two sites can be tested more directly on shorter cyclic versions of tetraloops which lack stems. Preliminary results comparing the $K_{\mathrm{i}}$ of a cyclic tetraloop analog with the $K_{\mathrm{m}}$ for its second site deadenylation suggest that the binding affinity of RTA for the second site adenosine is $\sim 15$-fold lower than the first (43). This difference is $\sim 100$-fold in case of the stem-loop substrate, $8 \mathrm{vdA}-10$ and suggests that the stem plays a role in the directionality of binding $\left(5^{\prime} \rightarrow 3^{\prime}\right.$ versus $\left.3^{\prime} \rightarrow 5^{\prime}\right)$.

\section{8-Vinyladenine: Synthesis and physicochemical characterization}

Characterization of 8-vinyladenine has not been previously reported (44). A standard of 8vinyladenine was synthesized for accurate quantitation of the hydrolytic rate of this novel nucleobase from the parent RNA. The precursor, "1", was treated with triethylamine in methanol ( $24 \mathrm{hrs}$ at $\mathrm{rt}$ ) to remove the formamidine followed by $15 \%$ dichloroacetic acid in dichloromethane for $3 \mathrm{hrs}$ to remove the 5'-dimethoxytrityl group and cleave the glycosidic bond in one step (see inset in Figure 10). The product was purified on a semi-preparative C18 reverse phase column. The identity of the product was confirmed by ${ }^{1} \mathrm{H}$ NMR and ESI mass analysis in the negative mode.

Absorption spectra of known quantities of 8-vinyladenine were recorded to determine its extinction coefficient. The $\lambda_{\max }$ was $275 \mathrm{~nm}$ and the absorption profile was broad with a spectral maximum between $270-290 \mathrm{~nm}$. The millimolar extinction coefficient, $\varepsilon$, was determined to be 8.33. 8-vA was also characterized as a fluorophore (see Figure 2 and Table 1). As described earlier, the $\lambda_{\mathrm{em}}$ was $378 \mathrm{~nm}$. The quantum yield, $\phi$, was determined to be 0.37 relative to tryptophan $(\phi=0.14)$ (45) and 0.33 relative to 2 -aminopurine $(\phi=0.66)$ (27). These determinations were made on absorbance matched samples in water at $\mathrm{pH} 7.0$ and $25^{\circ} \mathrm{C}$. The extended conjugation of 8 -vinyladenine makes it a better leaving group than adenine. However, activation of adenine as a leaving group by RTA is proposed to occur via protonation of N7 and/or possibly $\mathrm{N} 3$. We were interested in determining the effect of the vinyl group on the $\mathrm{p} K_{\mathrm{a}}$ values of these ring nitrogens and therefore on leaving group activation. ${ }^{1} \mathrm{H}$ NMR was used to follow the change in chemical shift of the vinyl $\mathbf{C} \underline{\mathbf{H}}=\mathrm{CH}_{2}$ proton and the proton at $\mathbf{C 8}$ of the purine ring with $\mathrm{pH}$ (Figure 10). The former is sensitive to changes in the environment of $\mathrm{N} 9$ and the latter to $\mathrm{N} 1$ or $\mathrm{N} 3$, which are not distinguished in this experiment. The NMR titration data was fitted to a biphasic $\mathrm{p} K_{\mathrm{a}}$ equation with two $\mathrm{p} K_{\mathrm{a}}$ 's. The $\mathrm{p} K_{\mathrm{a}}$ for N9 of 8-vA was found to be 9.5 and that for the N1 -N3 system to be 4.6. These numbers are similar to those of adenine with a $\mathrm{p} K_{\mathrm{a}}$ of 9.8 for $\mathrm{N} 9$. Thus, introduction of the vinyl group only reduces the $\mathrm{p} K_{\mathrm{a}}$ at $\mathrm{N} 9$ by $\sim 0.2-0.3$ units.

Since the $\mathrm{p} K_{\mathrm{a}}$ of $\mathrm{N} 7$ cannot be determined from the NMR experiment, equilibrium geometries of 2'-deoxyadenosine (dAde) and 8-vinyl-2'-deoxyadenosine were optimized using the B3LYP/6-31G(d,p) level of theory with Gaussian 03 (46). The atomic electrostatic potential (ESP) charges using Merz-Singh-Kollman (MK) scheme were computed at the same level of calculation. Charges at N7 in the two molecules were similar (-0.563 and -0.559 respectively) suggesting that the $\mathrm{p} K_{\mathrm{a}}$ at $\mathrm{N} 7$ might also be similar (Figure $\mathrm{S} 4$ in supporting information). The $\mathrm{p} K_{\mathrm{a}}$ data and charge calculations along with the dynamics simulations suggest that steric factors enforced by the vinyl group orient the ribosyl group such that electronic factors from the enzyme then stabilize the ground state. Thus, electronic properties (of adenine and 8-vA) alone do not bring about the observed difference in catalysis of A-10 versus 8vdA-10. 
The similarity between the $K_{\mathrm{d}}$ of $\mathbf{8 v d A - 1 0}$ and the $K_{\mathrm{m}}$ of $\mathbf{A - 1 0}$ (also a dissociation constant) suggests that binding is driven by extended structural contacts over the stem-loop (electronic and hydrophobic), whereas catalysis is driven by optimization of electronic interactions (such as H-bonding) to both adenine and ribose at the transition state. Non-enzymatic hydrolysis of 8-vA from 8vdA-10, albeit slow, confirms that it is an activated leaving group. Among the host of transition state analog inhibitors designed for RTA, only those with small hydrophobic leaving groups (such as phenyl) bind more tightly than those with adenine analogs designed to provide a better $\mathrm{p} K_{\mathrm{a}}$ match (11). This suggests that the high specificity of the RTA active site is due to efficient recognition of subtle electronic and steric properties of the RNA molecules. The extreme specificity of RTA is reflected in its hydrolysis of a single adenosine in the milieu of adenosines in ribosomal RNA.

\section{Rate of Non-Enzymatic Release of 8-Vinyladenine from 8vdA-10}

The change in fluorescence intensity of $8 \mathrm{vdA}-10$ was recorded as a function of time to determine the rate of 8-vA release. As mentioned earlier, the fluorescence intensity of the 8vinyladenine in stem-loop RNA is dependent on the conformation of the tetraloop.

A 270 fold reduction in fluorescence intensity is observed when $8 \mathrm{vdA}$ is incorporated in the tetraloop of $8 \mathrm{vdA}-10$. 8-vA release from $8 \mathrm{vdA}-10$ was followed at $\mathrm{pH} 4.0(10 \mathrm{mM}$ citrate buffer) over $10 \mathrm{hrs}$. The rate constant $\left(\mathrm{k}_{4}\right.$ in Scheme 1$)$ was $6 \times 10^{-5}$ nmoles $\mathrm{min}^{-1}$. This rate is $\sim 300$ fold slower than the release of adenine from the second site $\left(k_{\text {cat }}\right.$ of $\sim 0.02 \mathrm{~min}^{-1}: \mathrm{k}_{3}$ in Scheme 1) by RTA. The rate constant was determined from the change in fluorescence intensity of a $5 \mu \mathrm{M}$ solution of $8 \mathrm{vdA}-10$ at $25^{\circ} \mathrm{C}$ (Figure 11).

Control experiments in a pH 7.6 buffer showed $<1 \%$ change in fluorescence intensity over 12 hrs consistent with a stable tetraloop conformation and an insignificant hydrolytic rate. A comparison of the non-enzymatic 8 -vinyladenine release rate versus enzymatic adenine release established that deadenylation of the tetraloop occurred with 8-vinyl-2'-deoxyadenosine still intact in the loop. A negligible change in fluorescence intensity was observed during the initial time course kinetics of adenine release from the second site in the tetraloop. It must be noted that since the quantum yield of 8-vA is 130 fold greater than that of 8-vinyl-2'-deoxyadenosine within the RNA, it is possible to determine very small release rates.

\section{Kinetics of A-14 turnover by Pokeweed Antiviral Protein (PAP)}

Of the various RIP's, Pokeweed Antiviral Protein (PAP) isolated from the leaves of Phytolacca americana, has been shown to have a broad RNA substrate specificity relative to the GAGA tetraloop specificity of RTA (47). Given this promiscuity of PAP, we decided to test its catalytic activity on 8vdA-10. Rajamohan et al. showed that both wild type and recombinant PAP were able to deadenylate $E$. coli $23 \mathrm{~S}$ and $16 \mathrm{~S}$ rRNA in $25 \mathrm{mM}$ Tris/ $\mathrm{HCl}$ at $\mathrm{pH} 7.8$ (48). The same $\mathrm{pH}$ conditions were used to test $8 \mathrm{vdA}-10$ as a PAP substrate. Before testing the hypothesis of $8 \mathrm{vdA}-10$ turnover by PAP, it was necessary to investigate the depurinating ability of PAP on a small stem-loop SRL RNA mimic, A-14.

PAP was heat treated to remove the non-specific glycosidase/nuclease activity while retaining the RNA N-glycosidase activity (49). Adenine release was detected on incubating A-14 with a commercial source wild type PAP at pH 7.8 ( $25 \mathrm{mM}$ Tris/HCl buffer). The $K_{\mathrm{m}}$ for A-14 was $220 \pm 20 \mu \mathrm{M}$ and the $k_{\text {cat }}$ was $2.9 \pm 0.2 \mathrm{~min}^{-1}$ (Figure S3B in supporting information). For comparison, the $K_{\mathrm{m}}$ and $k_{\mathrm{cat}}$ of A-14 hydrolysis by RTA are $8.1 \mu \mathrm{M}$ and $219 \mathrm{~min}^{-1}$ respectively (12). It is remarkable that RTA has optimal activity at $\mathrm{pH} 4.0$ but is inactive at neutral $\mathrm{pH}$ for hydrolysis of small stem-loop RNA whereas PAP can operate at neutral $\mathrm{pH}$ albeit not efficiently. Having established that A-14 is a substrate of PAP, we tested its ability to hydrolyze $8 \mathrm{vdA}-10$ under neutral $\mathrm{pH}$ conditions. 


\section{Hydrolysis of $8 \mathrm{vdA}-10$ by PAP}

Incubation of 8vdA-10 with PAP at pH 7.8 (25 mM HEPES buffer) resulted in release of both adenine and of 8-vinyladenine. Adenine release occured at an initial rate of $0.018 \mathrm{~min}^{-1}$. Kinetic characterization of $8 \mathrm{vdA}-10$ binding to PAP indicated a $K_{\mathrm{m}}>300 \mu \mathrm{M}$ for this substrate. The release of 8-vinyladenine, measured by the continuous change in fluorescence intensity of a 5 $\mu \mathrm{M}$ solution of 8vdA-10 on incubation with $1 \mu \mathrm{M}$ PAP, was determined to be $\sim 1.6 \times 10^{-3}$ $\mathrm{min}^{-1}$ which is 10 -fold lower than the rate of adenine release from the second site. These results establish that 8-vA is released by PAP, but not as efficiently as adenine from the second site. The RTA active site is highly stringent in comparison and does not catalyze 8-vA release.

\section{Conclusions}

We have designed a new RNA/DNA hybrid substrate analog, 8vdA-10, that binds to RTA with a $K_{\mathrm{i}}$ value similar to the $K_{\mathrm{m}}$ of the small stem-loop RNA 10-mer, A-10. Despite having an activated leaving group, the $\mathrm{N}$-glycosidic bond of the 8-vinyl-2'-deoxyadenosine in the RNA is not cleaved by RTA. Dynamics calculations suggest that steric factors cause the nucleoside to bind in an orientation where the enzyme destabilizes the formation of the oxacarbenium ion and thus precludes catalysis. However, adenine is released from the second site of 8vdA-10. This deadenylation rate is 2 orders of magnitude slower than that measured for depurination of the first site adenosine in A-10. The binding affinity of $\mathbf{8 v d A - 1 0}$ to the catalytic site that results in the second site depurination is $\sim 100$ fold lower than to the first, indicating an alternate binding geometry for the modified vinyl RNA. The new stem-loop analog described here thus allows a comparison of the enzymatic specificities for the two adenosines in a tetraloop RNA structure since the first site is still intact when the second site depurination occurs. The results with PAP suggest that second site depurination can also occur at neutral $\mathrm{pH}$. Glycosidic bond scission at a specific site on the $28 \mathrm{~S}$ rRNA by ribosome binding proteins is stringent under physiological conditions. However, multiple adenine release from truncated stem-loop RNA analogs suggests that non-hydrolyzable adenine isosteres at both sites in the GAGA tetraloop might be of interest for inhibitor design. Our study complements the work of Mély et al. and shows that the 8-vinyl moiety is a useful fluorophore system that can be exploited further to study protein-RNA complexes.

\section{Supplementary Material}

Refer to Web version on PubMed Central for supplementary material.

\section{Acknowledgements}

This work was supported by NIH Grant CA7244. We thank Mr. Matthew Sturm for valuable discussions and Dr. Steven D. Schwartz for providing the computing resource for the molecular dynamics simulations.

\section{References}

1. Endo Y, Chan YL, Lin A, Tsurugi K, Wool IG. The cytotoxins alpha-sarcin and ricin retain their specificity when tested on a synthetic oligoribonucleotide (35-mer) that mimics a region of $28 \mathrm{~S}$ ribosomal ribonucleic acid. J Biol Chem 1988;263:7917-7920. [PubMed: 3372511]

2. Kudlicki W, Kitaoka Y, Odom OW, Kramer G, Hardesty B. Elongation and folding of nascent ricin chains as peptidyl-tRNA on ribosomes: the effect of amino acid deletions on these processes. J Mol Biol 1995;252:203-212. [PubMed: 7674301]

3. Moazed D, Robertson J, Noller H. Interaction of elongation factors EF-G and EF-Tu with a conserved loop in 23S RNA. Nature 1988;334:362-364. [PubMed: 2455872] 
4. Endo Y, Tsurugi K. The RNA N-glycosidase activity of ricin A-chain. The characteristics of the enzymatic activity of ricin A-chain with ribosomes and with rRNA. J Biol Chem 1988;263:87358739. [PubMed: 3288622]

5. Sandvig K, van Deurs B. Transport of protein toxins into cells: pathways used by ricin, cholera toxin and Shiga toxin. FEBS Lett 2002;529:49-53. [PubMed: 12354612]

6. Lord JM, Deeks E, Marsden CJ, Moore K, Pateman C, Smith DC, Spooner RA, Watson P, Roberts LM. Retrograde transport of toxins across the endoplasmic reticulum membrane. Biochem Soc Trans 2003;31:1260-1262. [PubMed: 14641038]

7. Eiklid K, Olsnes S, Pihl A. Entry of lethal doses of abrin, ricin and modeccin into the cytosol of HeLa cells. Exp Cell Res 1980;126:321-326. [PubMed: 7363949]

8. Rich V. Murderous experiments of Stalin's police chief. New Sci 1992;135:8.

9. Remnick D. Washington Post 1992 April 21;:D1.

10. Ler SG, Lee FK, Gopalakrishnakone P. Trends in detection of warfare agents Detection methods for ricin, staphylococcal enterotoxin B and T-2 toxin. J Chromatogr A 2006;1133:1-12. [PubMed: 16996531]

11. Roday S, Amukele T, Evans GB, Tyler PC, Furneaux RH, Schramm VL. Inhibition of ricin A-chain with pyrrolidine mimics of the oxacarbenium ion transition state. Biochemistry 2004;43:4923-4933. [PubMed: 15109250]

12. Chen XY, Link TM, Schramm VL. Ricin A-chain: kinetics, mechanism, and RNA stem-loop inhibitors. Biochemistry 1998;37:11605-11613. [PubMed: 9708998]

13. Orita M, Nishikawa F, Kohno T, Senda T, Mitsui Y, Yaeta E, Kazunari T, Nishikawa S. Highresolution NMR study of a GdAGA tetranucleotide loop that is an improved substrate for ricin, a cytotoxic plant protein. Nucleic Acids Res 1996;24:611-618. [PubMed: 8604301]

14. Chen XY, Berti PJ, Schramm VL. Ricin A-Chain: Kinetic Isotope Effects and Transition State Structure with Stem-Loop RNA. J Am Chem Soc 2000;122:1609-1617.

15. Ben Gaied N, Glasser N, Ramalanjaona N, Beltz H, Wolff P, Marquet R, Burger A, Mély Y. 8-vinyldeoxyadenosine, an alternative fluorescent nucleoside analog to 2'-deoxyribosyl-2-aminopurine with improved properties. Nucleic Acids Res 2005;33:1031-1039. [PubMed: 15718302]

16. Manfredini S, Baraldi PG, Bazzanini R, Marangoni M, Simoni D, Balzarini J, De Clercq E. Synthesis and cytotoxic activity of 6-vinyl- and 6-ethynyluridine and 8-vinyl-and 8-ethynyladenosine. J Med Chem 1995;38:199-203. [PubMed: 7837231]

17. Segel, I. Enzyme Kinetics. Wiley Classics Library Edition. John Wiley \& Sons; New York: 1993.

18. Lakowicz, JR. Principles of Fluorescence Spectroscopy. 2. Kluwer Academic/Plenum Publishers; New York: 1999.

19. Monzingo AF, Robertus JD. X-ray analysis of substrate analogs in the ricin A-chain active site. J Mol Biol 1992;227:1136-1145. [PubMed: 1433290]

20. Rutenber E, Katzin BJ, Ernst S, Collins EJ, Mlsna D, Ready MP, Robertus JD. Crystallographic refinement of ricin to $2.5 \AA$. Proteins 1991;10:240-250. [PubMed: 1881880]

21. Brook CL III, Karplus MJ. Deformable stochastic boundaries in molecular dynamics. J Chem Phys 1983;79:6312-6325.

22. Brooks BR, Bruccoleri RE, Olafson BD, States DJ, Swaminathan S, Karplus M. CHARMM: A program for macromolecular energy, minimization, and dynamics calculations. J Comput Chem $1983 ; 4: 187-217$.

23. Jorgensen WL, Chandrasekhar J, Madura JD, Impey RW, Klein ML. Comparison of simple potential functions for simulating liquid water. J Chem Phys 1983;79:926-935.

24. Brook CL III, Karplus M. Solvent effects on protein motion and protein effects on solvent motion. J Mol Biol 1989;208:159-181. [PubMed: 2769750]

25. Ryckaert J-P, Ciccoti G, Berendsen HJC. Numerical integration of the cartesian equations of motion of a system with constraints: Molecular dynamics of n-alkanes. J Comput Phys 1977;23:327-341.

26. Alul RH, Singman CN, Zhang GR, Letsinger RL. Oxalyl-CPG: a labile support for synthesis of sensitive oligonucleotide derivatives. Nucleic Acids Res 1991;19:1527-1532. [PubMed: 2027761]

27. Sproat B, Colonna F, Mullah B, Tsou D, Andrus A, Hampel A, Vinayak R. An Efficient Method for the Isolation and Purification of Oligoribonucleotides. Nucleosides Nucleotides 1995;14:255-273. 
28. Ward DC, Reich E, Stryer L. Fluorescence studies of nucleotides and polynucleotides. I. Formycin, 2-aminopurine riboside, 2,6-diaminopurine riboside, and their derivatives. J Biol Chem 1969;244:1228. [PubMed: 5767305]

29. Jucker FM, Heus HA, Yip PF, Moors EH, Pardi A. A network of heterogeneous hydrogen bonds in GNRA tetraloops. J Mol Biol 1996;264:968-80. [PubMed: 9000624]

30. Correll CC, Munishkin A, Chan YL, Ren Z, Wool IG, Steitz TA. Crystal structure of the ribosomal RNA domain essential for binding elongation factors. Proc Natl Acad Sci U S A 1998;95:1343613441. [PubMed: 9811818]

31. Kenfack CA, Burger A, Mèly Y. Excited-state properties and transitions of fluorescent 8-vinyl adenosine in DNA. J Phys Chem B Condens Matter Mater Surf Interfaces Biophys 2006;110:2632726336. [PubMed: 17181292]

32. Chen XY, Berti PJ, Schramm VL. Transition-State Analysis for Depurination of DNA by Ricin AChain. J Am Chem Soc 2000;122:6527-6534.

33. Tang S, Xie L, Hou F, Liu WY, Ruan K. Non-specific deadenylation and deguanylation of naked RNA catalyzed by ricin under acidic condition. Biochim Biophys Acta 2001;1519:192-198. [PubMed: 11418185]

34. Yang X, Gerczei T, Glover LT, Correll CC. Crystal structures of restrictocin-inhibitor complexes with implications for RNA recognition and base flipping. Nat Struct Biol 2001;8:968-973. [PubMed: 11685244]

35. Olson MA. Ricin A-chain structural determinant for binding substrate analogues: a molecular dynamics simulation analysis. Proteins: Structure, Function, and Genetics 1997;27:80-95.

36. Kim Y, Mlsna D, Monzingo AF, Ready MP, Frankel A, Robertus JD. Structure of a ricin mutant showing rescue of activity by a noncatalytic residue. Biochemistry 1992;31:3294-3296. [PubMed: 1348187]

37. Singh V, Schramm VL. Transition-state structure of human 5'-methylthioadenosine phosphorylase. J Am Chem Soc 2006;128:14691-14696. [PubMed: 17090056]

38. Nunez S, Antoniou D, Schramm VL, Schwartz SD. Promoting vibrations in human purine nucleoside phosphorylase. A molecular dynamics and hybrid quantum mechanical/molecular mechanical study. J Am Chem Soc 2004;126:15720-15729. [PubMed: 15571394]

39. Sorin EJ, Engelhardt MA, Herschlag D, Pande VS. RNA simulations: probing hairpin unfolding and the dynamics of a GNRA tetraloop. J Mol Biol 2002;317:493-506. [PubMed: 11955005]

40. Schaerer OD, Verdine GL. A Designed Inhibitor of Base-Excision DNA Repair. J Am Chem Soc 1995; 117:10781-10782.

41. Walter AE, Turner DH, Kim J, Lyttle MH, Müller P, Mathews DH, Zuker M. Coaxial stacking of helixes enhances binding of oligoribonucleotides and improves predictions of RNA folding. Proc Natl Acad Sci USA 1994;91:9218-9222. [PubMed: 7524072]

42. Steffen P, Voss B, Rehmsmeier M, Reeder J, Giegerich R. RNAshapes: an integrated RNA analysis package based on abstract shapes. Bioinformatics 2006;22:500-503. [PubMed: 16357029]

43. Sturm M, Roday S, Schramm VL. 2006Unpublished results

44. Lang P, Magnin G, Mathis G, Burger A, Biellmann J-F. Synthesis of 8-(omega-Hydroxyalkyl)-, 8(omega-hydroxyalk-1-enyl)-, and 8-(omega-hydroxy-3-alk-1-ynyl)adenines using the tertbutyldimethylsilyloxymethyl group, a new and versatile protecting group of adenine. J Org Chem 2000;65:7825-7832. [PubMed: 11073587]

45. Kirby EP, Steiner RF. Influence of solvent and temperature upon the fluorescence of indole derivatives. J Phys Chem 1970;74:4480-4490.

46. Frisch, MJ.; Trucks, GW.; Schlegel, HB.; Scuseria, GE.; Robb, MA.; Cheeseman, JR.; Zakrzewski, VG.; Montgomery, JA., Jr; Stratmann, RE.; Burant, JC.; Dapprich, S.; Millam, JM.; Daniels, AD.; Kudin, KN.; Strain, MC.; Farkas, OJ.; Tomasi, BV.; Cossi, M.; Cammi, R.; Mennucci, B.; Pomelli, C.; Adamo, C.; Clifford, S.; Ochterski, J.; Petersson, GA.; Ayala, PY.; Cui, Q.; Morokuma, K.; Malick, DK.; Rabuck, AD.; Raghavachari, K.; Foresman, JB.; Cioslowski, J.; Ortiz, JV.; Stefanov, BB.; Liu, G.; Liashenko, A.; Piskorz, P.; Komaromi, I.; Gomperts, R.; Martin, RL.; Fox, DJ.; Keith, T.; Al-Laham, MA.; Peng, CY.; Nanayakkara, A.; Gonzalez, C.; Challacombe, M.; Gill, PMW.; Johnson, B.; Chen, W.; Wong, MW.; Andres, JL.; Gonzalez, C.; Head-Gordon, M.; Replogle, ES.; Pople, JA. Gaussian 03, revision B.04. Gaussian; Pittsburgh, PA: 2003. 
47. Parikh BA, Tumer NE. Antiviral activity of ribosome inactivating proteins in medicine. Mini Rev Med Chem 2004;4:523-543. [PubMed: 15180509]

48. Rajamohan F, Mao C, Uckun FM. Binding interactions between the active center cleft of recombinant pokeweed antiviral protein and the alpha-sarcin/ricin stem loop of ribosomal RNA. J Biol Chem 2001;276:24075-24081. [PubMed: 11313342]

49. Day PJ, Lord JM, Roberts LM. The deoxyribonuclease activity attributed to ribosome-inactivating proteins is due to contamination. Eur J Biochem 1998;258:540-545. [PubMed: 9874221]

\section{Abbreviations}

8vdA

8-vinyl-2'-deoxyadenosine

8-vA

8-vinyladenine

8vdA-10

8vdA incorporated into a 10-mer stem-loop RNA with the sequence, 5'CGCG8vdAGAGCG-3'

\section{8vAde}

8-vinyladenosine

RTA

Ricin Toxin A-Chain

PAP

Pokeweed Antiviral Protein

KIE's

Kinetic Isotope Effects

A-10

stem-loop RNA with the sequence, 5'-CGCGAGAGCG-3'

A-14

stem-loop RNA with the sequence, 5'-CGCGCGAGAGCGCG-3'

ApG

adenyl-3,'5'-guanosine

vApG

8-vinyladenyl-3',5' '-guanosine

dApG

2'-deoxyadenyl-3,'5'-guanosine

vdApG

2'-deoxy-8- vinyladenyl-3',5' -guanosine 


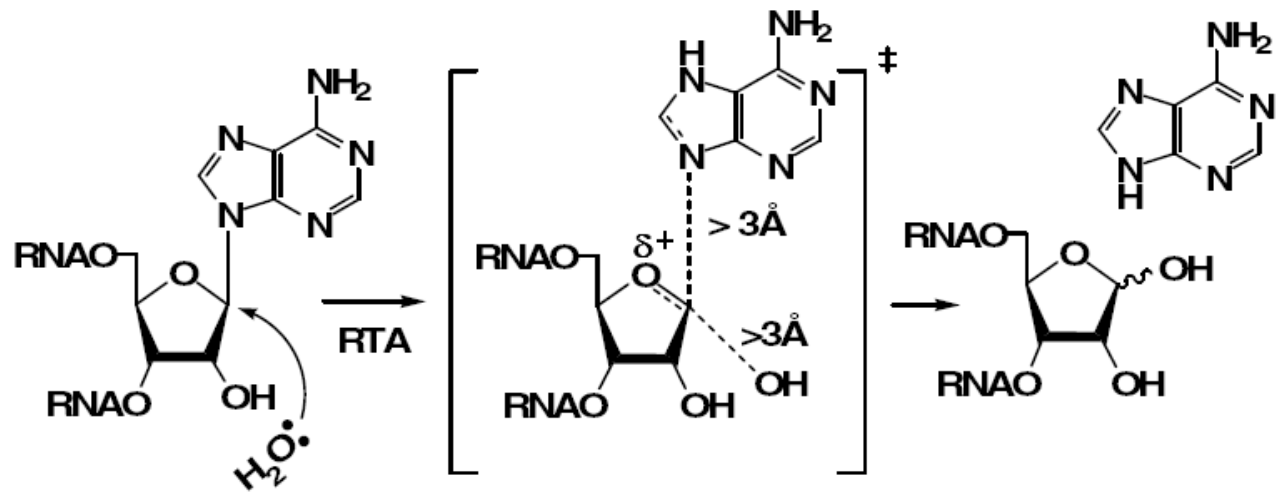

Figure 1.

The hydrolytic cleavage of an adenosine moiety catalyzed by RTA proceeds through an oxacarbenium ion transition state. 

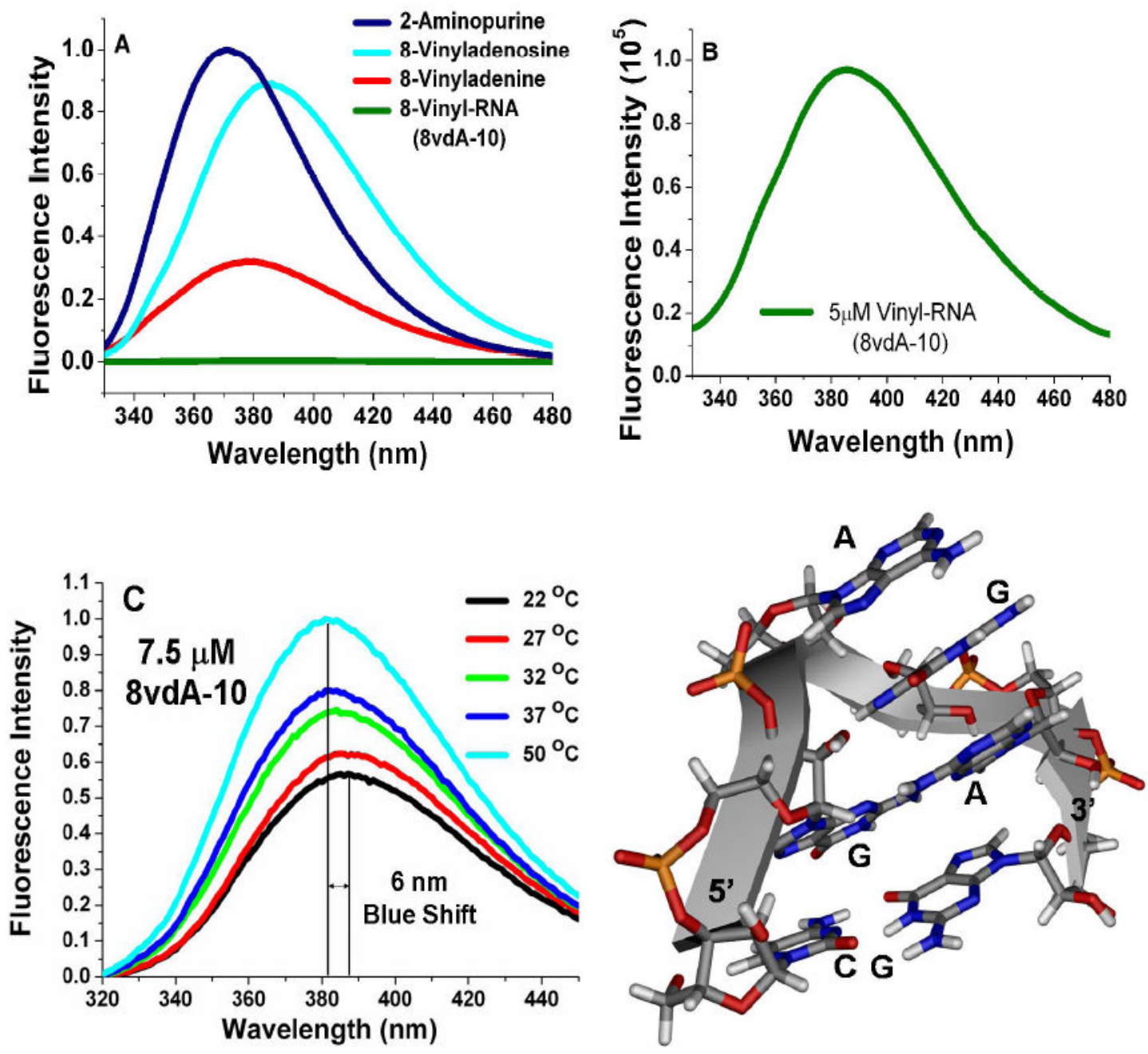

Figure 2.

A) Normalized fluorescence intensities of equimolar concentrations of 2-AP, 8vAde, 8vdA and $8 \mathrm{vdA}-10$ in water at $\mathrm{pH} 7.0$ and $25^{\circ} \mathrm{C} \mathrm{B}$ ) Absolute fluorescence intensity of a $5 \mu \mathrm{M}$ solution of $8 \mathrm{vdA}-10$ in $10 \mathrm{mM}$ phosphate/0.1mM EDTA buffer, $\mathrm{pH} 7.1$ and $25^{\circ} \mathrm{C}$. C) Normalized fluorescence intensities of a $7.5 \mu \mathrm{M}$ solution of $8 \mathrm{vdA}-10$ in $10 \mathrm{mM}$ citrate/0.1mM EDTA buffer, $\mathrm{pH} 4.0$ and D) The structure of the GAGA tetraloop (PDB ID: 1ZIG). ${ }^{29}$ The tetraloop residues are shown as stick models. Residues A, G and A on the 3' -side of the loop form a triple purine stack. The first adenosine on the 5'-side is depurinated by RTA. 

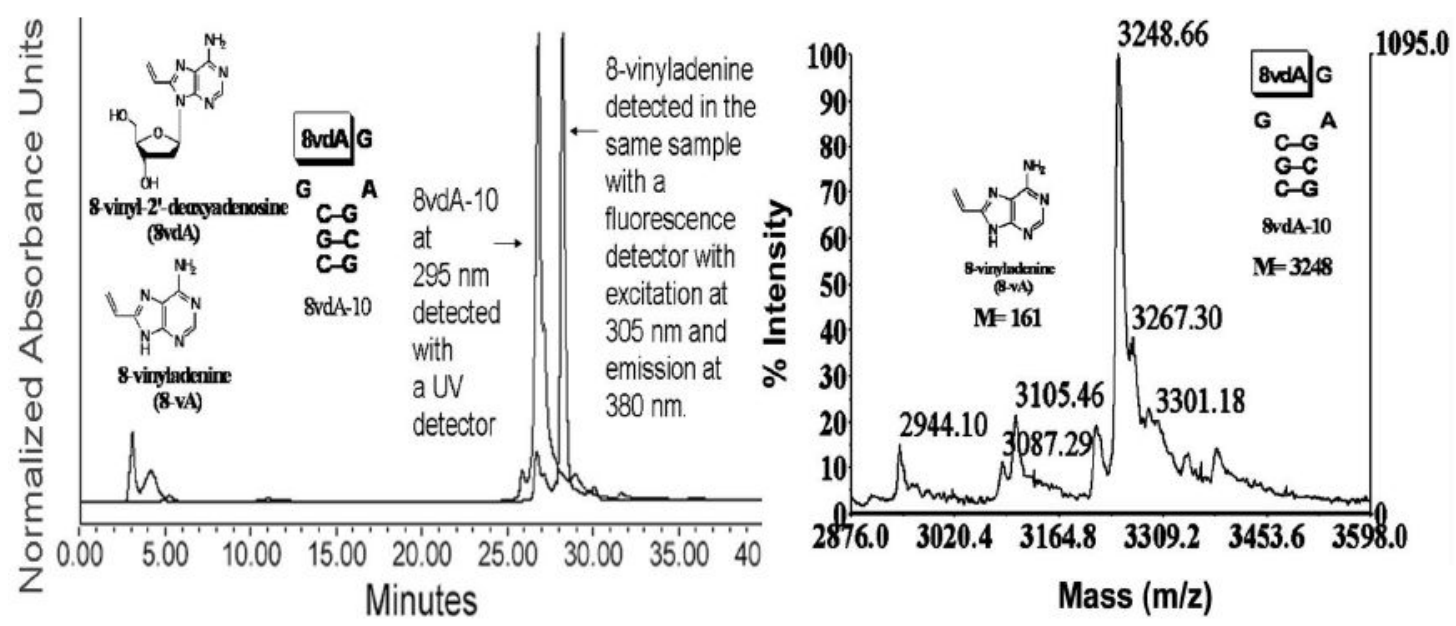

Figure 3.

Left Panel: HPLC profile of $8 \mathrm{vdA}-10$ upon incubation at $37{ }^{\circ} \mathrm{C}$ for 12 hours in $10 \mathrm{mM}$ citrate buffer, $\mathrm{pH}$ 4.0. The peak at 27 minutes corresponds to the RNA (8vdA-10) and the peak at 29 minutes corresponds to 8-vinyladenine. The latter was undetectable at $260 \mathrm{~nm}$. However, it can be detected either at $305 \mathrm{~nm}$ (where the sensitivity of detection is $\sim 40$ pmoles) or by a fluorescence detector set at an excitation wavelength of $305 \mathrm{~nm}$ and emission of $380 \mathrm{~nm}$. Right Panel: MALDI spectrum of $8 \mathrm{vdA}-10$ upon incubation at $37^{\circ} \mathrm{C}$ for 12 hours in $10 \mathrm{mM}$ citrate buffer, $\mathrm{pH} 4.0$ shows the loss of 8-vinyladenine (M-161; the peak with mass 3105 is the $\left[\mathrm{M}^{+}\right.$ $+\mathrm{NH}_{4}^{+}$] peak). 

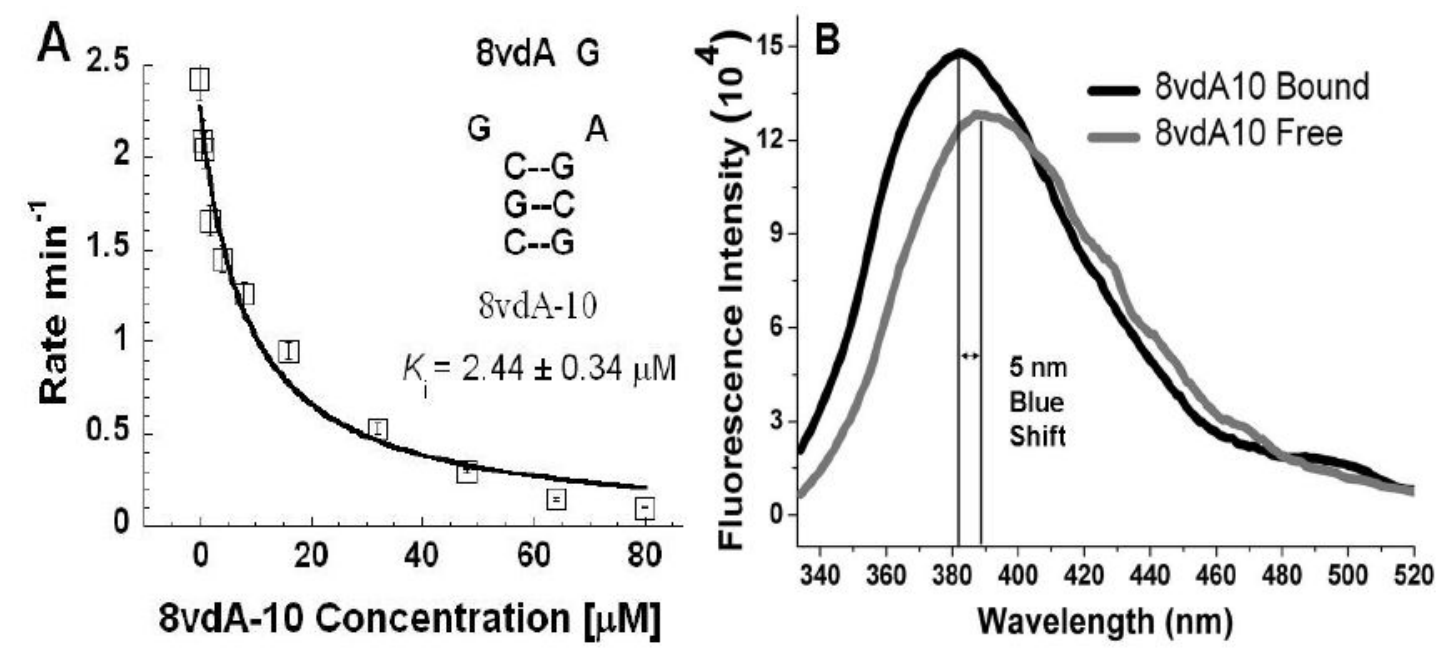

Figure 4.

A) The binding constant for $8 \mathrm{vdA}-10$ to RTA, $K_{\mathrm{i}}$, was determined from fits of initial rate data for the competitive substrate, A-10 at a given concentration of $8 \mathrm{vdA}-10$ to the equation $v=$ $k_{\text {cat }}[\mathrm{S}] /\left[[\mathrm{S}]+K_{\mathrm{m}}\left(1+I / K_{\mathrm{i}}\right)\right]$. B) Fluorescence intensities of the free and bound form of $8 \mathrm{vdA}-10$. Binding of the RNA to RTA causes a $5 \mathrm{~nm}$ blue shift in the emission maximum. 

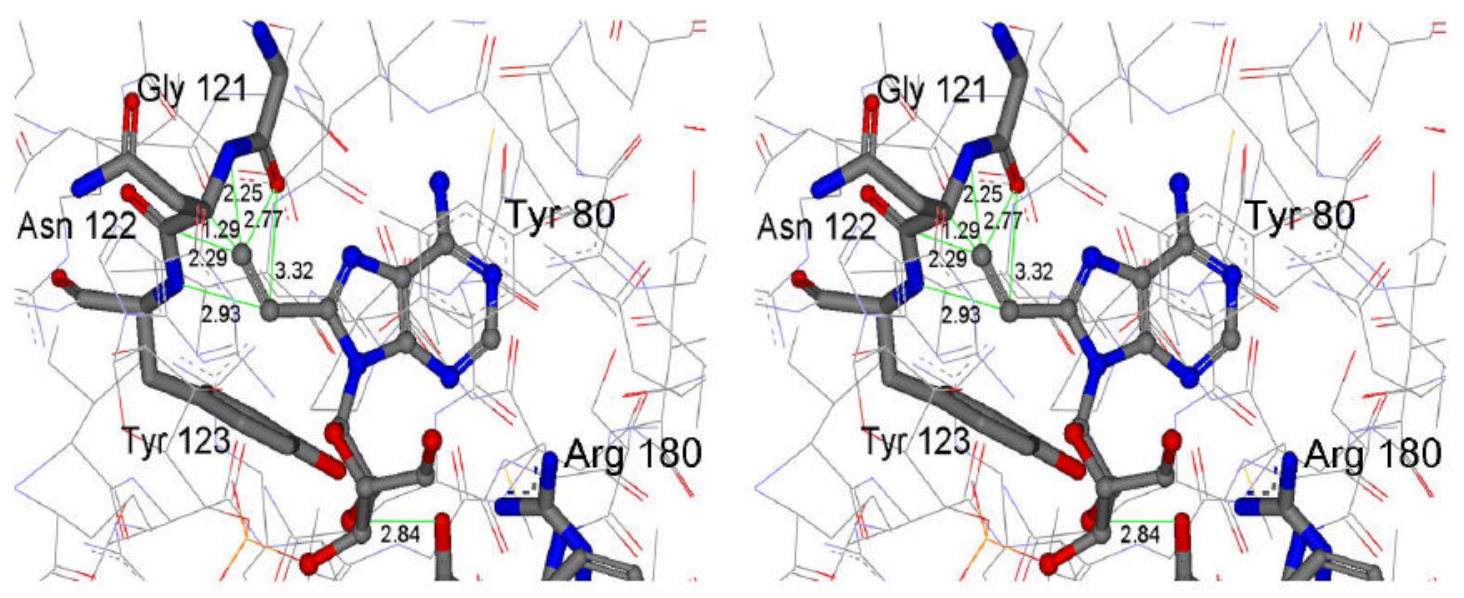

Figure 5.

Stereoview of a docking model of 8-vinyladenine interactions in the active site of RTA created by superimposition on the coordinates of adenine in the crystal structure of RTA bound to the dinucleotide adenyl-3',5'-guanosine (PDB ID: 1APG). The vinyl moiety experiences steric clashes with the carbonyl oxygen of Gly 121 , the backbone amide and the $\alpha$ and $\beta$ carbons of Asn 122 and the backbone amide and the aromatic ring of Tyr 123. 

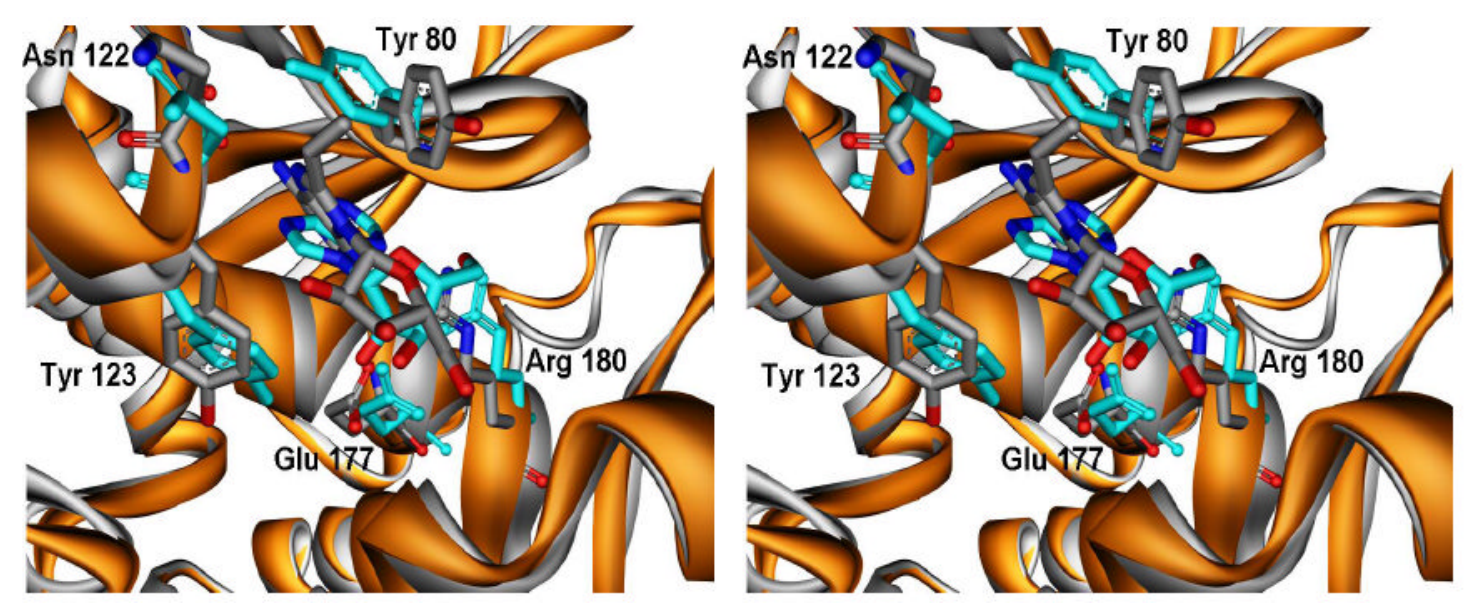

Figure 6.

Stereoview of the superimposition of 300 ps simulated structures of RTA-ApG (cyan with ligand heteroatoms colored by atom type) and RTA-vApG (shown in grey with heteroatoms colored by atom type). The $\mathrm{C}-\mathrm{N}$ glycosidic bond dihedral rotates by $\sim 33^{\circ}$ for the vinyladenosine which is accompanied by changes in side chain dihedral angles of Tyr 80 and Tyr 123 . The 8vinyladenine base avoids steric clashes with Asn 122 and Tyr 123 (compare with Figure 5). 


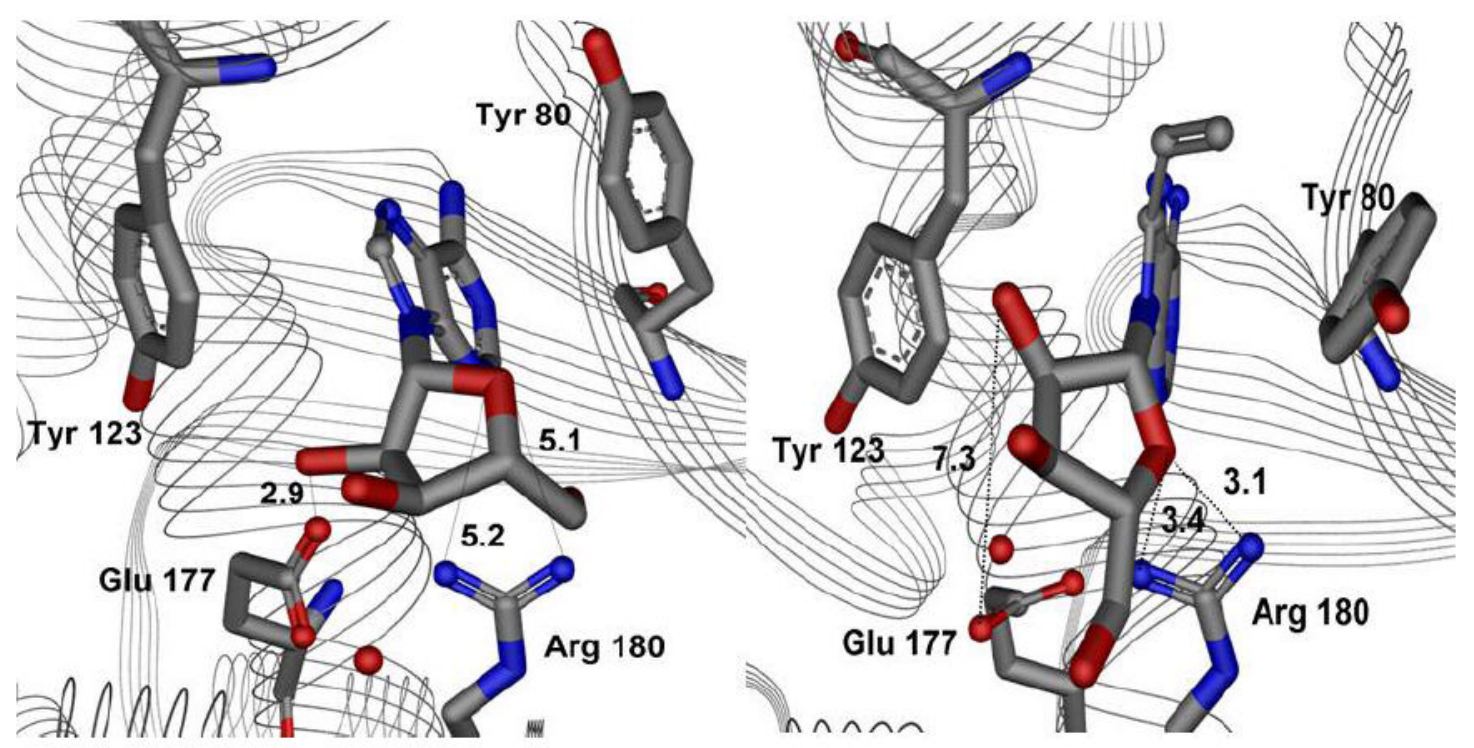

Figure 7.

Active site interaction distances $(\AA)$ for 300 ps simulation structures of ApG (left panel) and the vinyl dinucleotide, $\mathrm{vApG}$ (right). Sterics reorganize the 8 -vinyladenine base binding pocket and also reorient the ribosyl group. The guanidinium nitrogens of Arg 180 in the RTA- vApG complex close in on the ribosyl O4' by $1.8 \AA$ for $\mathrm{NH} 1$ and $2.1 \AA$ for the $\mathrm{NH} 2$, suggesting stronger sugar-Arg 180 interactions. The 2'-hydroxyl-Glu 177 interaction is also lost as this distance extends from $2.9 \AA$ to $7.3 \AA$. 


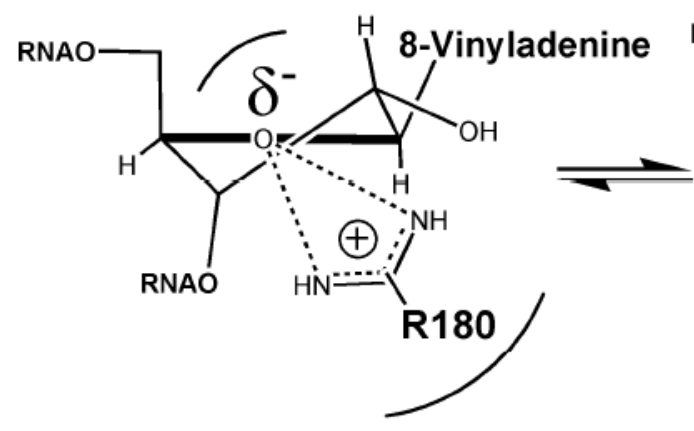

Electrostatic Stabilization

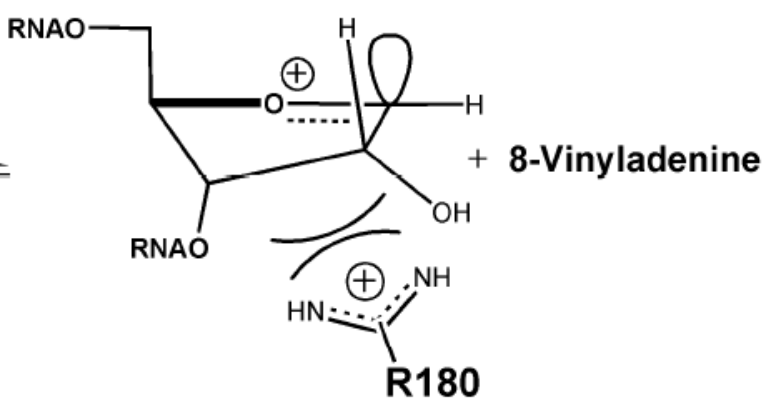

Oxacarbenium ion Destabilization

Figure 8.

A model to explain the lack of catalysis by RTA of the 8-vinyladenyl substituted RNA, 8vdA-10. Dynamics simulations predict Arg 180 within $3 \AA$ distance from the ribose 4'hydroxyl. The consequence of this could be electrostatic stabilization of the ground state such that the formation of the oxacarbenium ion is destabilized and the reaction stalled. 
$1^{\text {st }}$ site depurination $2^{\text {nd }}$ site depurination

$K_{\mathrm{m}}=2.9 \mu \mathrm{M}$

$k_{\text {cat }}=4 \mathrm{~min}^{-1}$

$\downarrow$

$A_{1} \mathbf{G}$

G $\quad A_{2}$

C-G

G-C

${ }^{\prime} \mathrm{C}^{-\mathrm{G}_{3}}$

TL1
$K_{\mathrm{m}}=205 \mu \mathrm{M}$

$k_{\text {cat }}=0.02 \mathrm{~min}^{-1}$
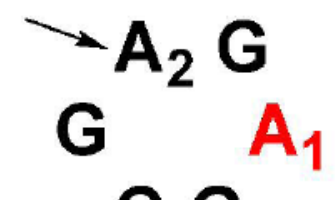

C-G

${ }_{3}, \mathrm{G}-\mathrm{C}$

G

$\mathrm{C}_{5}$ '

$$
\begin{gathered}
\Delta \mathrm{G}_{\text {calc }}=-4.4 \mathrm{kcal} / \mathrm{mol} \quad \Delta \mathrm{G}_{\text {calc }}=1.7 \mathrm{kcal} / \mathrm{mol} \\
\Delta \Delta \mathrm{G}_{\text {inter }}=6.1 \mathrm{kcal} / \mathrm{mol} \\
\Delta \Delta \mathrm{G}^{\mathrm{TS}}=\Delta \mathrm{G}_{\mathrm{TL} 1}^{\mathrm{TS}}-\Delta \mathrm{G}^{\mathrm{TS}}{ }_{\mathrm{TL} 2}=\sim 3.1 \mathrm{kcal} / \mathrm{mol}
\end{gathered}
$$

Figure 9.

Substrate slippage model for RTA catalysis at the second adenosine site in the tetraloop. Two possible stem-tetraloop structures of A-10 calculated with the programs mFold and RNAshapes are shown. The barrier to interconversion between TL1 and TL2 in solution is higher than the difference in transition state energies for catalysis at the two sites. 

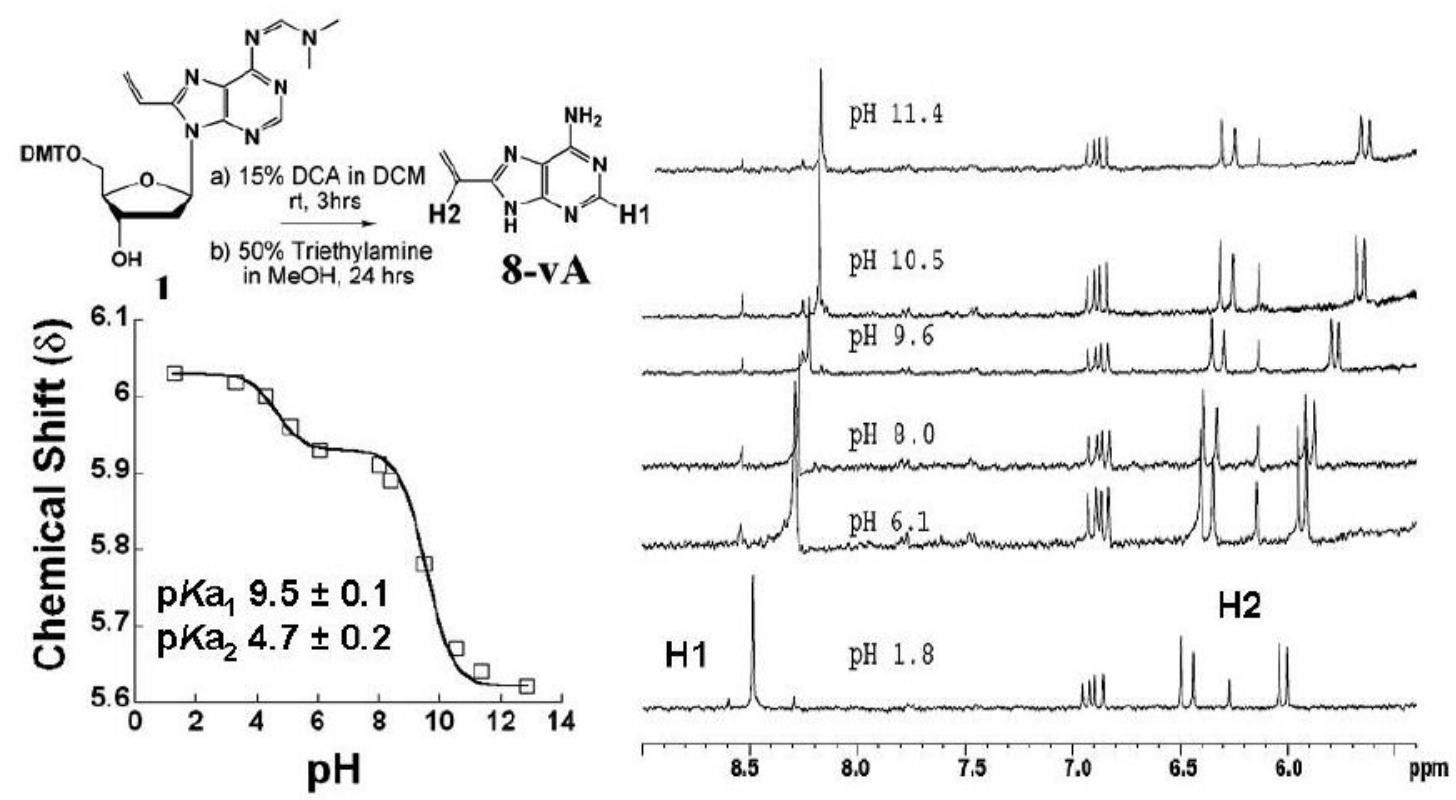

Figure 10.

Determination of the $\mathrm{p} K_{\mathrm{a}}$ of $\mathrm{N} 9$ in 8 -vinyladenine by ${ }^{1} \mathrm{H}$ NMR. Data fitting is described in the text. The chemical shifts of the vinylic proton, $\mathbf{H} 2$ (doublet), in the $6 \mathrm{ppm}$ region and that of the ring proton, $\mathbf{H 1}$ (singlet), in the $8.5 \mathrm{ppm}$ region report on two protonation events, hence the biphasic curve. The inset shows the synthesis of 8-vinyladenine (8vA). Prolonged treatment of the dimethoxytritylated precursor nucleoside, $\mathbf{1}$, under acidic conditions effected the removal of the DMT protecting group as well as cleavage of the glycosidic bond. The N6 protection was removed under basic conditions and the final compound was purified by reverse phase HPLC. 


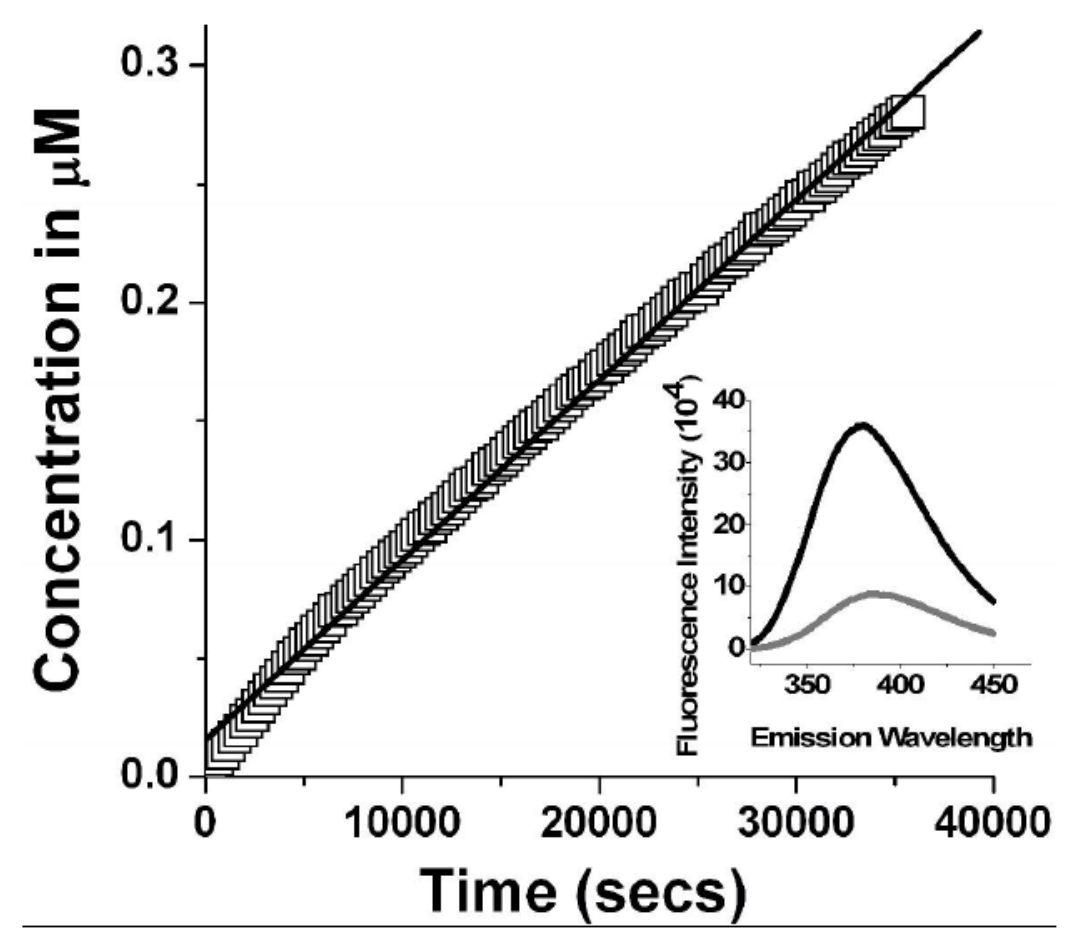

Figure 11.

Continuous release of 8-vinyladenine from the stem-loop oligomer, 8vdA-10 over 10 hrs in 10 $\mathrm{mM}$ citrate buffer, $\mathrm{pH} 4.0$. The rate constant was derived from a fit to the equation: $k=(1 / \Delta \alpha)$ $(\Delta \mathrm{F} / \Delta \mathrm{t})$ where $\Delta \mathrm{F} / \Delta \mathrm{t}$ is the rate in fluorescence units $\mathrm{s}^{-1}, \Delta \alpha=\mathrm{F}_{\text {tot }} /[\mathrm{S}]_{\text {tot }}$, where $\mathrm{F}_{\text {tot }}$ is the total fluorescence increase for $100 \%$ conversion of substrate $\left([\mathrm{S}]_{\text {tot }}\right)$ to product. Excitation was set at $305 \mathrm{~nm}$ and the emission spectrum was recorded in the $320-450 \mathrm{~nm}$ range. 


\section{dab G \\ 8vdA G \\ 8vdA G}

G

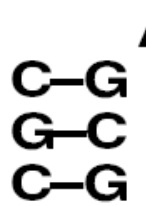
$A \longleftarrow \sqrt{8}$
8-vinyladenine
${ }^{\mathbf{G}} \begin{array}{r}\mathbf{C}-\mathbf{G} \\ \mathbf{G}-\mathbf{C} \\ \mathbf{C}-\mathbf{G}\end{array}$
$A \longrightarrow$
Adenine

G

dab-RNA

8vdA-10

G-C

C--G

ab-RNA

8vdA = 8-vinyl-2'-deoxyadenosine; dab = "deoxyribo"abasic site; $a b=$ "ribo"-abasic site

8-Vinyladenine

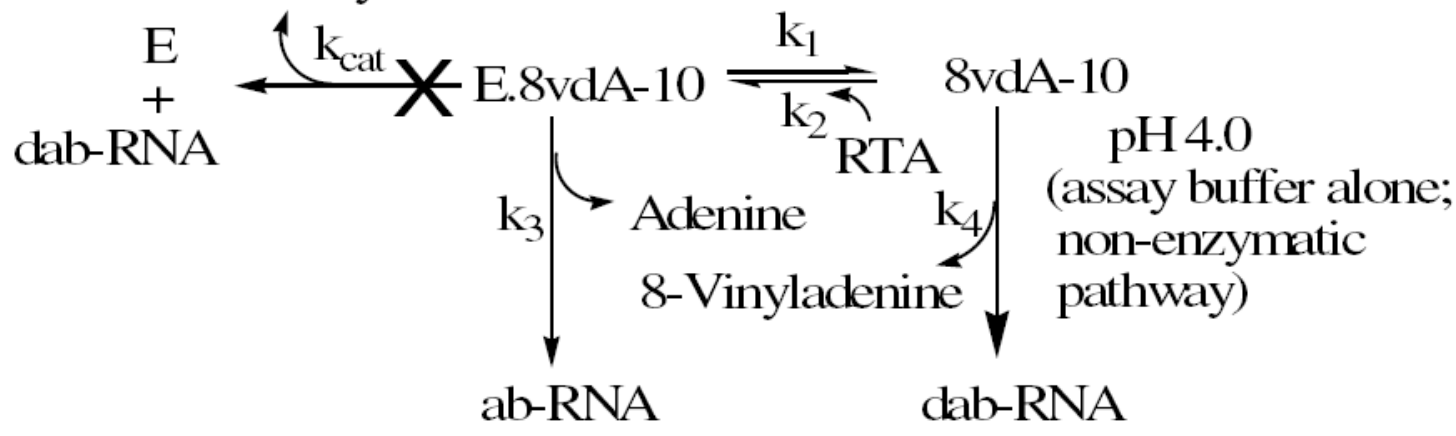

Scheme 1.

The fate of the stem-loop RNA, 8vdA-10 under enzymatic and non-enzymatic conditions. $8 \mathrm{vdA}-10$ binds to RTA $\left(K_{\mathrm{i}}=\mathrm{k}_{2} / k_{1}\right)$ but is not hydrolyzed. Instead, adenine is released from the second site in the tetraloop $\left(\mathrm{k}_{3}\right)$. However a competing non-enzymatic process in the $\mathrm{pH}$ 4.0 assay buffer results in depurination $\left(\mathrm{k}_{4}\right)$. 


\section{Table 1}

Relative quantum yields of the 8-vinyl nucleosides, the base and the RNA 10-mer oligonucleotide sequence. 8vinyladenosine was synthesized using the procedure reported by Manfredini et al. (16).

\begin{tabular}{ccc}
\hline Molecule & $\lambda_{\text {em }}$ & $\boldsymbol{\phi}$ \\
\hline 2-Aminopurine (2-AP) (27) & $370 \mathrm{~nm}$ & 0.66 \\
8-Vinyl-2'-deoxyadenosine (8vdA) (15) & $384 \mathrm{~nm}$ & 0.68 \\
8-Vinyladenosine (8vAde)* & $384 \mathrm{~nm}$ & $378 \mathrm{~nm}$ \\
8-Vinyladenine (8-vA) & $\mathbf{3 8 8} \mathbf{~ n m}$ & 0.66 \\
$\mathbf{8 - V i n y l - R N A ~ ( 1 0 - m e r , ~ 8 v d A - 1 0 )}$ & & $\mathbf{0 . 0 0 2 5}$ \\
\hline
\end{tabular}


Roday et al.

Page 31

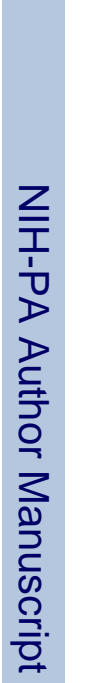

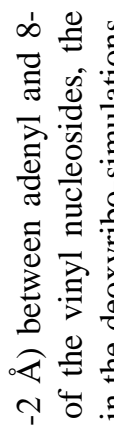

$\simeq 0 \circ \varangle$

क छ

迥

递家家

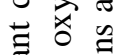

$\stackrel{\leftrightarrow}{\Xi}$.

突

क

要 \&

Е $\cong$

Z म

I $\stackrel{0}{0}$ ลे

$>$ 管

ट $\frac{0}{\pi} \cdot \frac{1}{4}$

은

$3 \quad 00$

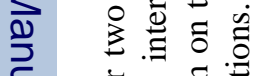

क

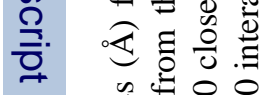

幽 $\infty$

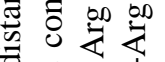

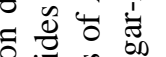

.气

ए气

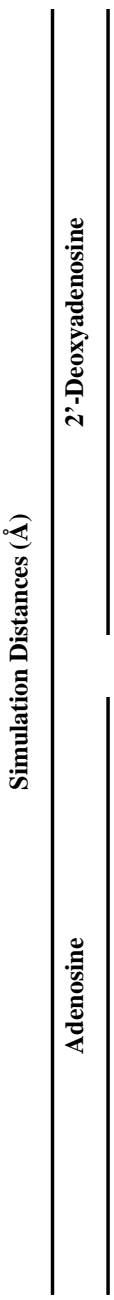

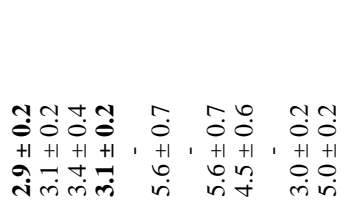

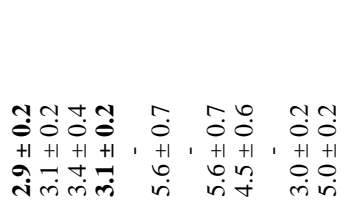

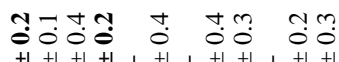

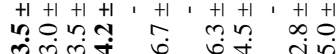

$\approx$

जिलो

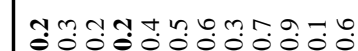

$+1+1+1+1+1+1+1+1+1+1+1+1$

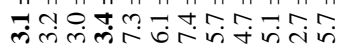

$\approx$

लिलिखिए

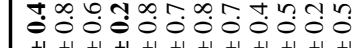

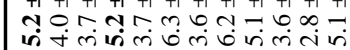

$\approx$

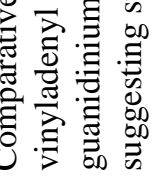

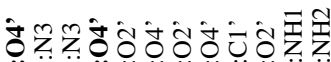

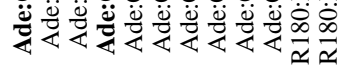

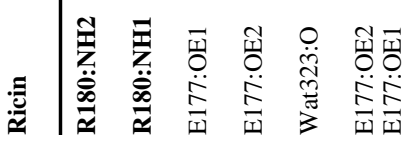

Biochemistry. Author manuscript; available in PMC 2008 September 16. 
Roday et al.

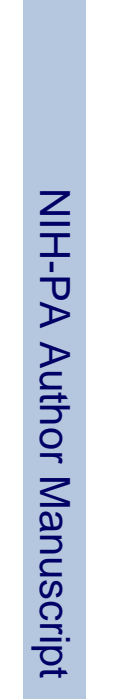

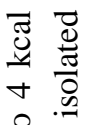

冚胥

过

ट्टे

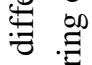

.

ब

可

氖

$\infty$

क

छे

토 융

$\dot{0} 0$

.

至 $\quad$ 离

宁范速

$>$ D

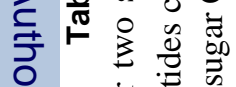

ㄴㅎㅁ

임

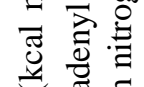

.

$\bar{\phi}$ i

¿

.들

迅 范

Z

预

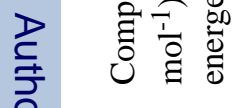

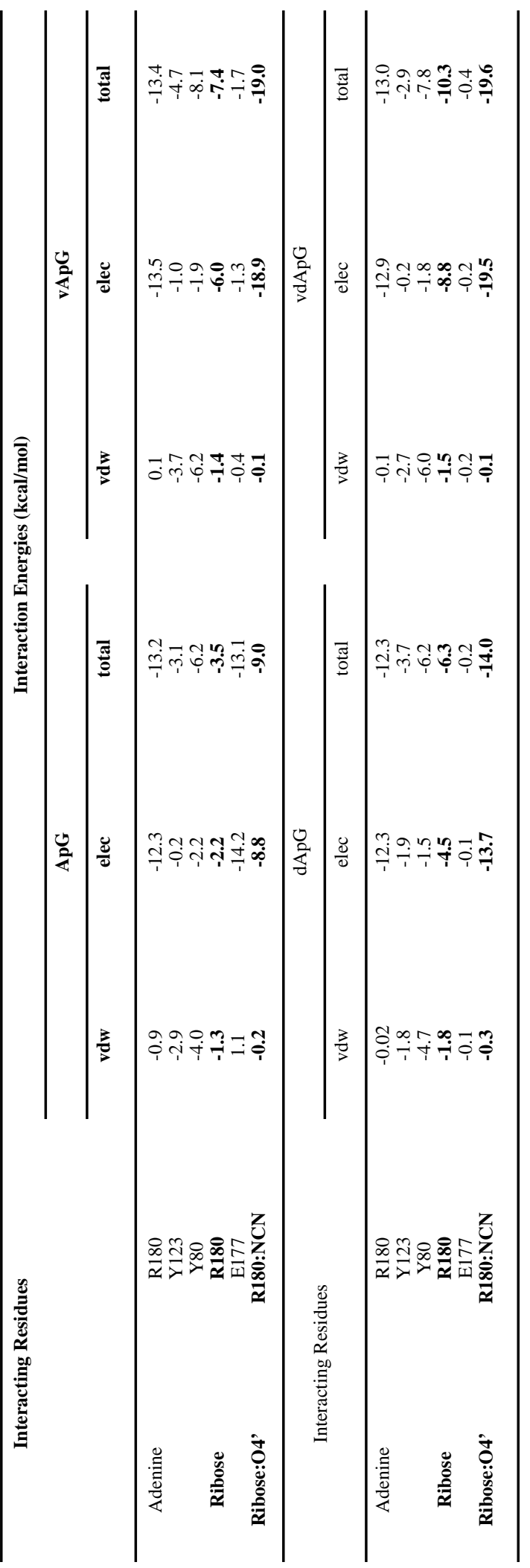

흠

Biochemistry. Author manuscript; available in PMC 2008 September 16. 